\title{
Reduced hippocampal inhibition and enhanced autism- epilepsy comorbidity in mice lacking neuropilin 2
}

\author{
Carol Eisenberg ${ }^{1,5}$, Deepak Subramanian ${ }^{2,3,5}$, Milad Afrasiabi ${ }^{2,5}$, Patryk Ziobro ${ }^{1,4}$, Jack DeLucia (iD ${ }^{1}$, Pamela R. Hirschberg (iD ${ }^{2}$, \\ Michael W. Shiflett ${ }^{4}$, Vijayalakshmi Santhakumar ${ }^{2,3^{凶}}$ and Tracy S. Tran (iD ${ }^{{ }^{凶}}$
}

This is a U.S. government work and not under copyright protection in the U.S.; foreign copyright protection may apply 2021

The neuropilin receptors and their secreted semaphorin ligands play key roles in brain circuit development by regulating numerous crucial neuronal processes, including the maturation of synapses and migration of GABAergic interneurons. Consistent with its developmental roles, the neuropilin 2 ( Nrp2) locus contains polymorphisms in patients with autism spectrum disorder (ASD). Nrp2-deficient mice show autism-like behavioral deficits and propensity to develop seizures. In order to determine the pathophysiology in Nrp2 deficiency, we examined the hippocampal numbers of interneuron subtypes and inhibitory regulation of hippocampal CA1 pyramidal neurons in mice lacking one or both copies of Nrp2. Immunostaining for interneuron subtypes revealed that $\mathrm{Nrp2}^{-1-}$ mice have a reduced number of parvalbumin, somatostatin, and neuropeptide $\mathrm{Y}$ cells, mainly in CA1. Whole-cell recordings identified reduced firing and hyperpolarized shift in resting membrane potential in CA1 pyramidal neurons from $\mathrm{Nrp2}^{+/-}$and $\mathrm{Nrp2}^{-/-}$mice compared to age-matched wild-type controls indicating decrease in intrinsic excitability. Simultaneously, the frequency and amplitude of spontaneous inhibitory postsynaptic currents (sIPSCs) are reduced in Nrp2deficient mice. A convulsive dose of kainic acid evoked electrographic and behavioral seizures with significantly shorter latency, longer duration, and higher severity in $\mathrm{Nrp2}^{-/-}$compared to $\mathrm{Nrp2}^{+/+}$animals. Finally, $\mathrm{Nrp2} 2^{+/-}$and $\mathrm{Nrp2} 2^{-/-}$but not $\mathrm{Nrp2} 2^{+/+}$, mice have impaired cognitive flexibility demonstrated by reward-based reversal learning, a task associated with hippocampal circuit function. Together these data demonstrate a broad reduction in interneuron subtypes and compromised inhibition in CA1 of $\mathrm{Nrp} 2^{-/-}$mice, which could contribute to the heightened seizure susceptibility and behavioral deficits consistent with an ASD/ epilepsy phenotype.

Translational Psychiatry (2021)11:537; https://doi.org/10.1038/s41398-021-01655-6

\section{INTRODUCTION}

Epilepsy and autism spectrum disorders (ASD) exhibit a remarkable degree of comorbidity, suggesting shared pathological mechanisms [1, 2]. Developmental anomalies in inhibitory circuit formation can severely compromise the fine balance between neuronal excitation and inhibition $(E / I)$ and have been proposed as candidate mechanisms linking childhood epilepsies and ASD [3-6]. Nevertheless, the link between the factors regulating the formation of GABAergic circuits during development, their impact on cellular and synaptic inhibition, and the risk for developing seizures and autism-like behavioral traits remain to be established.

Signaling of class 3 secreted semaphorins with their holoreceptors, Neuropilins (Nrp), and Plexins (Plxn) [7, 8], are essential for wiring neural circuits by controlling neuronal morphogenesis, cell migration, axon guidance, synapse formation, and survival [9-13]. Nrp2 is expressed in inhibitory neuron precursor cells in the median ganglionic eminence (MGE) where it is regulated by the transcription factor Nkx2.1 and is essential for normal cortical interneuron migration [14]. MGE-derived cortical/hippocampal neurons include parvalbumin (PV) and somatostatin (SOM) interneurons that mediate proximal and distal dendritic inhibition, as well as neuropeptide $Y$
(NPY) expressing neurons [14-16]. PV neurons are numerically fewer and functionally impaired in developmental neuropsychiatric disorders including ASD and schizophrenia $[6,17]$, while SOM and NPY neurons are reduced in epilepsy [18]. Interestingly, mice with Nrp2 deletion $\left(\mathrm{Nrp}^{-1-}\right)$ were reported to have reduced GABAergic neurons in hippocampal subfields [19] and were found to be impaired in social object recognition and social novelty preference [20] consistent with a potential link between the reduction in interneurons and ASD-like phenotype. Importantly, mice with a single copy of $\mathrm{Nrp2}\left(\mathrm{Nrp}^{+/-}\right)$show increased susceptibility to induction of behavioral seizures, while mice with both copies deleted $\left(\mathrm{Nrp2}^{-1-}\right)$ were reported to exhibit seizures on handling [19] suggesting that loss of Nrp2 may also contribute to developmental epilepsy. Although the association between Nrp2 and human epilepsy is unclear [21], Nrp2 polymorphism is associated with autism in two patient populations $[22,23]$. Moreover, deletion of the Nrp2 ligand, semaphorin $3 \mathrm{~F}$ (Sema3F), in GABAergic neurons resulted in increased seizure susceptibility [24] and development of autism-like behaviors [25], suggesting that mice with deficient Nrp2 signaling could serve as a model to assess inhibitory circuit dysregulation associated with the propensity for autism/seizure phenotypes.

\footnotetext{
${ }^{1}$ Department of Biological Sciences, Rutgers University, Newark, NJ 07102, USA. ²Department of Pharmacology, Physiology and Neuroscience, Rutgers New Jersey Medical School, Newark, NJ 07103, USA. ${ }^{3}$ Department of Molecular, Cell and Systems Biology, University of California Riverside, Riverside, California, CA 92521, USA. ${ }^{\circ}$ Department of Psychology, Rutgers University, Newark, NJ 07102, USA. ${ }^{5}$ These authors contributed equally: Carol Eisenberg, Deepak Subramanian, Milad Afrasiabi. ${ }^{\circledR}$ email: vijayas@ucr.edu; tstran@rutgers.edu
} 
The hippocampal formation is a major focus of histological and electrophysiological abnormalities in temporal lobe epilepsy and is functionally compromised in rodent models with asocial/ autistic behaviors [26-29]. Nrp2 plays a role in the maturation of both glutamatergic and GABAergic circuits in the hippocampus. Nrp2 is expressed in hippocampal projection neurons where it regulates morphogenesis and excitatory synaptic function [3032]. Consistent with its role in interneuron migration, hippocampal GABAergic neurons, particularly NPY neurons, were found to be reduced in Nrp2-deficient mice [19]. Curiously, although PV and SOM neurons derive from the MGE and require Nrp2 for cortical migration [14, 19], limited loss of PV neurons and no reduction in SOM neurons were found in hippocampal subfields of $\mathrm{Nrp2}^{-1-}$ mice. This contrasts with the strong deficit in hippocampus-dependent behavioral tasks and propensity to seizures in Nrp2 mutant mice $[19,20]$. While significantly higher mEPSC frequencies, with no difference in amplitude, were reported in hippocampal granule cells from $\mathrm{Nrp2}^{-/-}$as compared to $\mathrm{Nrp2}^{+/+}$littermate controls [30], functional analysis of intrinsic physiology and inhibitory regulation of hippocampal principal neurons are needed to better inform the underlying circuit changes in these animals. Additionally, while $\mathrm{Nrp2}^{+/-}$mice failed to exhibit the significant behavioral deficits observed in $\mathrm{Nrp2}^{-/-}$ mice [20], both $\mathrm{Nrp2}^{+/-}$and $\mathrm{Nrp2}^{-/-}$mice were reported to have a comparable reduction in GABAergic neurons [19], suggesting that the reduction in interneurons and behavioral outcomes may be differentially impacted by the extent of Nrp2 deletion. However, whether $\mathrm{Nrp2}^{+/-}$and $\mathrm{Nrp2}^{-/-}$mice show differences in cellular and synaptic inhibition and seizure susceptibility has not been examined. This study was conducted to determine the effect of heterozygous and homozygous Nrp2 deletion on intrinsic physiology and inhibitory inputs to hippocampal CA1 pyramidal cells and assess whether there are genotypedependent increases in seizure susceptibility and memory/ learning deficits associated with ASD phenotypes.

\section{MATERIALS AND METHODS \\ Animals}

All experiments were performed in accordance with IACUC protocols approved by Rutgers University, Newark, NJ, and the University of California at Riverside, CA and in keeping with the ARRIVE guidelines. Neuropilin 2 (Nrp2) knockout mouse line has been described previously in detail [33]. Mice used in this study were backcrossed for at least 10 generations to the C57BL/6NTac background strain. Nrp2 genotypes were confirmed by using polymerase chain reaction (PCR).

\section{Immunostaining}

$\mathrm{Nrp2}^{+/+}$(wild-type), $\mathrm{Nrp2}^{+/-}$(heterozygote) and $\mathrm{Nrp2}^{-/-}$(homozygote) mice aged 3-6 months (average age of all genotype groups: $3.7 \pm 0.95$ months, four females and five males), when mice are considered to be in the mature adult stage [34], were subjected to transcardial perfusion with $4 \%$ paraformaldehyde (PFA). Brains were dissected, postfixed for $2 \mathrm{~h}$ in $4 \%$ PFA and then imbedded in OCT medium. Brains were sectioned on a cryostat at $20 \mu \mathrm{m}$ thickness at $200 \mu \mathrm{m}$ intervals through the anterior to the posterior extent of the hippocampus and cortex along the coronal plane. Sections were processed for immunocytochemistry as previously described [35], with the following modification. Coverslips were mounted on microscope slides using Mowiol (cat. No. 81381 Aldrich), plus 10\% p-Phenylenediamine (PPD, cat No. 78460) anti-fade mounting media. Primary antibodies used were: mouse monoclonal anti-Parvalbumin (1.5:500, Swant, PV235); mouse monoclonal anti-Parvalbumin (1:750, Sigma, P3088); rabbit polyclonal antineuropeptide $\mathrm{Y}(1: 1000$, Abcam, ab30914); rat monoclonal antiSomatostatin (1:150, Millipore, MAB354) and for visualization, AlexaFluor 488 or Cy5 (1:500, Jackson Immuno Research Laboratories); AlexaFluor 546 (1:500 Invitrogen).

\section{Cell counts and data analysis}

For cells containing parvalbumin (PV), Neuropeptide Y (NPY), and somatostatin (SOM), the soma was counted in four major regions: Dentate gyrus/hilar region/CA4 (DG) region, $C A 1, C A 2$, and CA3 regions as adapted from Gant, et al. [19]. Within these regions, PV, NPY, and SOM-stained cells were quantified in the entire hemi-hippocampus. Ten PV, NPY, SOM, and DAPI stained hemi-hippocampal sections (at $200 \mu \mathrm{m}$ intervals) per animal were counted using the ImageJ (Fiji) software. Experimenters, a total of two who independently counted the cells, were blinded to genotype. Average measures per animal were used for statistical analysis $(n=$ at least three animals/genotype). The total number of PV, NPY, and SOM cells were counted in the hippocampal region in each of 10 sections. Total counts were averaged together to establish a single value of cell counts per hemihippocampal region for each mouse.

\section{Photo-documentation}

All immunocytochemically processed brain sections were imaged using the Zen software (Zeiss) and Zeiss 510 LSC Confocal System. Representative nonoverlapping fields were imaged and stitched together to reconstruct hippocampal and cortical sections. Compiled $z$-stack images were exported as tif files. Images were captured with EC Plan-Neofluar 10X/ $0.30 \mathrm{M} 27$, and Plan-Neofluar 40x/1.3 Oil DIC and the following laser lines: $405,488,543$, and $633 \mathrm{~nm}$.

\section{Slice physiology}

Horizontal hippocampal slices $(350 \mu \mathrm{m})$ were prepared from 6-10-weekold male and female $\mathrm{Nrp2}^{+/+}, \mathrm{Nrp2}^{+/-}$and $\mathrm{Nrp2}^{-1-}$ mice following euthanasia under isoflurane anesthesia [36, 37]. Slices were prepared in ice-cold high Sucrose artificial Cerebro-Spinal Fluid (Sucrose-aCSF) that contained (in mM) $85 \mathrm{NaCl}, 75$ sucrose, $24 \mathrm{NaHCO}_{3}, 25$ glucose, $4 \mathrm{MgCl}_{2}$, $2.5 \mathrm{KCl}, 1.25 \mathrm{NaH}_{2} \mathrm{PO}_{4}$, and $0.5 \mathrm{CaCl}_{2}$ using Leica VT1000 or VT1200S Vibratomes (Wetzlar, Germany). Sliced were bisected and incubated at $32 \pm 1{ }^{\circ} \mathrm{C}$ for a minimum of $1 \mathrm{~h}$ in a submerged holding chamber containing recording aCSF (in mM) $126 \mathrm{NaCl}, 2.5 \mathrm{KCl}, 2 \mathrm{CaCl}_{2}, 2 \mathrm{MgCl}_{2}$, $1.25 \mathrm{NaH}_{2} \mathrm{PO}_{4}, 26 \mathrm{NaHCO}_{3}$, and 10 D-glucose and subsequently held at room temperature (RT). All solutions were saturated with $95 \% \mathrm{O}_{2}$ and $5 \%$ $\mathrm{CO}_{2}$ and maintained at a $\mathrm{pH}$ of 7.4 for 2-6 $\mathrm{h}[36,37]$.

Slices were transferred to a submerged recording chamber and perfused with oxygenated aCSF at $33 \pm 1{ }^{\circ} \mathrm{C}$ and CA1 pyramidal cells were patched under IR-DIC visualization using Nikon Eclipse FN-1 (Nikon Corporation, Shinagawa, Tokyo, Japan) or Olympus BX50 (Olympus Corporation, Shinjuku, Tokyo, Japan) microscope, using $40 \mathrm{X}$ water-immersion objectives and borosilicate microelectrodes (3-5 M $\Omega$ ). Whole-cell voltage- and current-clamp recordings were obtained using Axon Instruments Axopatch 200B or MultiClamp 700B amplifiers (Molecular Devices, Sunnyvale, CA). Data were low-pass filtered at $3 \mathrm{kHz}$, digitized using DigiData $1440 \mathrm{~A}$, and acquired using pClamp10 at $10-\mathrm{kHz}$ sampling frequency. The internal solution for recordings contained (in $\mathrm{mM}$ ) $125 \mathrm{KCl}, 10 \mathrm{~K}$-gluconate, 10 HEPES, 2 MgCl2, 0.2 EGTA, 2 Na-ATP, 0.5 Na-GTP, 10 PO Creatine, and 0.3\% Biocytin and was titrated to a pH 7.25 with $\mathrm{KOH}$ (270-290 mOsm). Recorded neurons were held in current clamp at $-60 \mathrm{mV}$ to elicit voltage responses to 500 milli-second positive and negative current steps. Active and passive properties, including spike frequency, action potential amplitude, spike frequency adaptation ratio, resting membrane potential, input resistance, and sag ratio were measured and calculated as described previously [36, 38]. Neurons were then held in voltage clamp at $-60 \mathrm{mV}$ to record SIPSCs which were isolated by the inclusion of the glutamate receptor antagonist, kynurenic acid (3 mM KyA, Tocris, Ellisville, MO) in the recording aCSF. Individual sIPSCs were detected using custom software in IgorPro7.0 (WaveMetrics, Lake Oswego, OR) and different parameters were analyzed. Events were visualized, and any "noise" that spuriously met trigger specifications was rejected. Cumulative probability plots of sIPSC parameters were constructed using IgorPro by pooling an equal number of sIPSCs from each cell [37].

\section{In vivo video-EEG recordings}

Seventeen mice $\left(6 \mathrm{Nrp2}^{+/+}, 6 \mathrm{Nrp2}^{+/-}\right.$, and $5 \mathrm{Nrp2}^{-/-}, 6-9$ months old) were surgically implanted with a tungsten wire electrodes $(50 \mu \mathrm{m}$, California Fine Wire company), placed over the granule cell layer of DG (AP:2 mm, ML: $1.2-1.5 \mathrm{~mm}$, DV: $1.7 \mathrm{~mm}$ from bregma) guided by periodic electrical stimulation of the angular bundle (AP: $-0.5 \mathrm{~mm}, \mathrm{ML}: 3.2 \mathrm{~mm}$, DV: - 0.8-1 mm from lambda). Two additional screw electrodes (invivo1, Roanoke, VA) on the contralateral side served as ground and reference. After 3-5 days of recovery, mice were connected to a tethered video-EEG monitoring system and baseline recordings were obtained for $30 \mathrm{~min}$. Signals were sampled at $10 \mathrm{kHz}$, amplified $(x 100,8202-\mathrm{SE} 3$, Pinnacle Technologies), digitized (Powerlabs16/35, AD Instruments), and recorded 
using LabChart 8.0 ( $A D$ instruments). Following baseline recordings, mice received a single high dose of $\mathrm{KA}(25 \mathrm{mg} / \mathrm{kg})$, and their latency to electrographic seizure, seizure duration, and severity were measured. Seizures were defined as rhythmic activity exceeding a threshold of mean baseline amplitude +2.5 standard deviation for $>5 \mathrm{~s}$ [39]. Artifacts due to electrical, exploratory, and grooming behavior were identified and removed manually from the raw EEG's before analysis. Seizures were scored based on a modified Racine scale [40] as: Stage-1, absence-like immobility; Stage-2, hunching with facial or manual automatisms; Stage-3, rearing with facial or manual automatisms and forelimb clonus; Stage-4, repeated rearing with continuous forelimb clonus and falling; and Stage-5, generalized tonic-clonic convulsions with lateral recumbence or jumping and wild running followed by generalized convulsions [41]. Seizure severity scores in the first $30 \mathrm{~min}$ were averaged over $10 \mathrm{~min}$ epochs. Cumulative seizure score was used to quantify overall seizure severity.

\section{Reversal-learning behavioral procedure}

A total of 15, 3-6 months old mice (average age of all genotype groups: $4 \pm 1.2$ months, 9 females and 6 males) were used for behavioral testing: 5 $\mathrm{Nrp2}^{-/-}, 5 \mathrm{Nrp2}^{+/-}$and $5 \mathrm{Nrp2}^{+/+}$. Mice were placed on a restricted food diet of approximately $2 \mathrm{~g}$ of standard chow each day. The chow (Purina, St. Louis MO, USA) was given in their home cage after behavioral procedures were complete. Animals were weighed daily, and their body weights were maintained to $85-90 \%$ of their original weight. Mice were tested in eight operant conditioning chambers (Med Associates, St. Albans VT, USA) as previously described [35]. Operant chamber operation and data collection were carried out with Med Associates proprietary software (Med-PC V). While placed on food restriction, mice were simultaneously habituated to the operant conditioning chamber for one 15 -min session. The next day, mice were conditioned to find pellets in the food cup in a 20-minute session in which food pellets were dispensed on a random-time $60 \mathrm{~s}$ schedule. Levers were retracted during this phase. The next day mice were trained to use levers. During each session, a single lever was inserted into the operant conditioning chamber. Each lever press resulted in the delivery of a single 20-mg grain-based chocolate flavored food pellet (Bio-serv, Frenchtown NJ USA) into the food cup. The session terminated after either 20 lever presses or $20 \mathrm{~min}$ elapsed from the start of the session. The mice completed two training sessions per day, one session with the left lever and one session with the right lever.

After all mice demonstrated proficiency in instrumental conditioning, they were placed on a reversal-learning task. In this phase both levers were extended simultaneously. One lever was designated as the rewarded lever, and the other lever as the nonrewarded lever. For each trial, responses on the rewarded lever always produced a food pellet, and responses on the nonrewarded lever never delivered a pellet. When no pellet was attained, both levers were retracted for $3 \mathrm{sec}$ and reinserted. After the mouse earned between 10 and 14 food pellets, the contingencies assigned to each lever were reversed; responses on the previously rewarded lever produced no pellets, whereas responses on the nonrewarded lever produced pellets. Mice remained in the operant chamber until 80 trials were completed/day or $1 \mathrm{~h}$ had passed since the start of the session. Mice underwent 15 reversal-learning sessions, one session per day. The training and testing regimen was completed in approximately 6 weeks, with 1 week of food restriction and habituation to the chambers, 2 weeks of instrumental training, and 3 weeks of reversal learning.

Task performance was evaluated by win/stay and lose/shift ratios for each animal. The win/stay ratio is calculated as win-stay divided by the total of win-stay and win-shift choices. Similarly, the lose/shift ratio is calculated as lose-shift divided by the total of lose-stay and lose-shift choices.

\section{Statistical analysis}

One-way or repeated-measure ANOVA (SigmaPlot 12.3) was used to test for statistical differences between the active and passive neuronal properties and IPSC parameters in electrophysiological recordings. For slice physiological recordings, the sample size is the number of cells and the number of mice they were obtained from is reported as well. The twoway ANOVA and post hoc Tukey's multiple comparison correction (Graph Pad Prism Software) were used for statistical differences in the cell counts and reversal-learning task. The Brown-Forsythe test was used to determine that variance between groups was not significantly different. A sample size requirement of three to seven animals was estimated by using $80 \%$ power and an effect size found in previous work and literature. Exclusion criteria of three standard deviations from the mean were pre-established for behavior tests. One mutant mouse performed over three standard deviations lower than the mean and was therefore eliminated from behavior analysis. One-way ANOVA ( $\mathrm{R}$ language) with post hoc multiple comparisons was used to test for statistical differences between the seizure parameters in vivo. Data that failed normality was analyzed using appropriate nonparametric tests. Significance was set to $p<0.05$. Data are shown as mean \pm SEM or median and interquartile range as appropriate.

\section{RESULTS}

Developmental Loss of Nrp2 significantly decreases the number of specific interneuron populations in the hippocampus

Nrp2 has been proposed to contribute to cortical and striatal interneuron numbers by regulating the migration patterns of MGE-derived interneuron progenitors [14, 42]. However, previous studies have reported a limited reduction in interneuronal numbers, restricted to NPY+ interneuronal subtype, in the hippocampal CA1 region of $\mathrm{Nrp2} 2^{-/-}$mice [19]. Therefore, we first asked whether the number of MGE-derived interneuron subtypes in the hippocampal CA1 is altered in $\mathrm{Nrp2}^{+/-}$and $\mathrm{Nrp2}^{-/-}$ compared to $\mathrm{Nrp}^{+/+}$littermates. We counted the numbers of specific interneuron populations using set parameters taken from ten coronal brain sections (at $20 \mu \mathrm{m}$ thickness) obtained at $200 \mu \mathrm{m}$ intervals through the entire anterior-posterior hemi-hippocampus.

First, we focused on the PV + interneurons, which include somatargeting fast-spiking basket cells, axo-axonic cells targeting the axon initial segment of principal cells, as well as classes of interneurons projecting to pyramidal cell dendrites $[43,44]$. We found significant decreases in PV + cell populations (Fig. 1A-E) between $\mathrm{Nrp2}^{-/-}$versus $\mathrm{Nrp2}^{+/+}, 38.2 \%$ in CA1 and $39.3 \%$ in CA2 (Fig. 1F; cell numbers in CA1: $24.18 \pm 2.33 \mathrm{Nrp2}^{+/+}, 21.62 \pm 1.35$ $\mathrm{Nrp2}^{+/-}, 14.95 \pm 1.14 \mathrm{Nrp2}^{-/-} ; F_{(2,24)}=11.13$ two-way ANOVA with Tukey's multiple comparison correction $p<0.0001$; cell numbers in CA2: $10.65 \pm 0.06 \mathrm{Nrp2}^{+/+}, 10.44 \pm 1.34 \mathrm{Nrp2}^{+/-}, 6.46 \pm 1.36 \mathrm{Nrp2}^{+/}$ ${ }^{+} ; F_{(2,24)}=11.13$ two-way ANOVA with Tukey's multiple comparison correction $p=0.0435$ ) as compared to previous report of a $27 \%$ reduction [19]. The overall reduction in PV + cells (Fig. 1G; total mean cell number: $48.44 \pm 4.8 \mathrm{Nrp2}^{+/+}, 47.55 \pm 2.76 \mathrm{Nrp2}^{+/-}$, $36.06 \pm 2.50 \mathrm{Nrp2}^{-1-} ; F_{(2,24)}=11.13$ two-way ANOVA with Tukey's multiple comparison correction $p=0.0004$ ) was $25.6 \%$ in all hippocampal regions in $\mathrm{Nrp2}^{-/-}$as compared to $\mathrm{Nrp2}^{+/+}$, with no difference between $\mathrm{Nrp2}^{+/+}$vs. $\mathrm{Nrp2} 2^{+/-}$animals.

Next we examined NPY + cells, which were previously reported to be decreased in the $\mathrm{Nrp2}^{-/-}$CA1 as compared to $\mathrm{Nrp2} 2^{+/+}$ littermates [19]. Our systematic analysis identified a $28.5 \%$ reduction in NPY+ neurons selectively in the CA1 region of $\mathrm{Nrp2}^{-/-}$mice as compared to $\mathrm{Nrp2} 2^{+/+}$littermates (Fig. $2 \mathrm{~A}-\mathrm{E}$ ), with no statistically significant differences detected in other hippocampal regions (Fig. 2F; cell numbers in CA1: $38.80 \pm 1.73 \mathrm{Nrp2}^{+/+}, 35.27 \pm 3.83$ $\mathrm{Nrp2}^{+/-}, 27.75 \pm 0.75 \mathrm{Nrp2}^{-/-} ; F_{(2,24)}=8.017$ two-way ANOVA with Tukey's multiple comparison correction $p=0.003)$. While there is an overall $24 \%$ reduction in NPY+ neurons of $\mathrm{Nrp2}^{-/-}$versus $\mathrm{Nrp2}^{+/+}$ littermates when all hippocampal subregions were combined (Fig. 2G; total mean cell number: $89.43 \pm 5.81 \mathrm{Nrp2} 2^{+/+}, 87.75 \pm 5.74$ $\mathrm{Nrp2}^{+/-}, 67.98 \pm 3.46 \mathrm{Nrp2}^{-/-} ; F_{(2,24)}=8.017$ two-way ANOVA with Tukey's multiple comparison correction $p=0.0040)$, differences between $\mathrm{Nrp2}^{+/-}$vs. $\mathrm{Nrp2}^{+/+}$animals failed to reach statistical significance (Fig. 2G).

Finally, we examined SOM + neurons, which specifically target dendrites and facilitate their inhibition. In contrast with the previous report of no change in SOM+ cell density [19], we found a striking reduction in SOM+ neurons in all hippocampal subfields of the $\mathrm{Nrp2}^{-1-}$ mutants as compared to littermate controls (Fig. 3). While we conducted quantitative cell counts of the entire anteriorposterior hippocampus for all subfields, we observe qualitatively a more dramatic difference in the number of SOM + neurons particularly from the posterior CA1 between the WT and Nrp2 


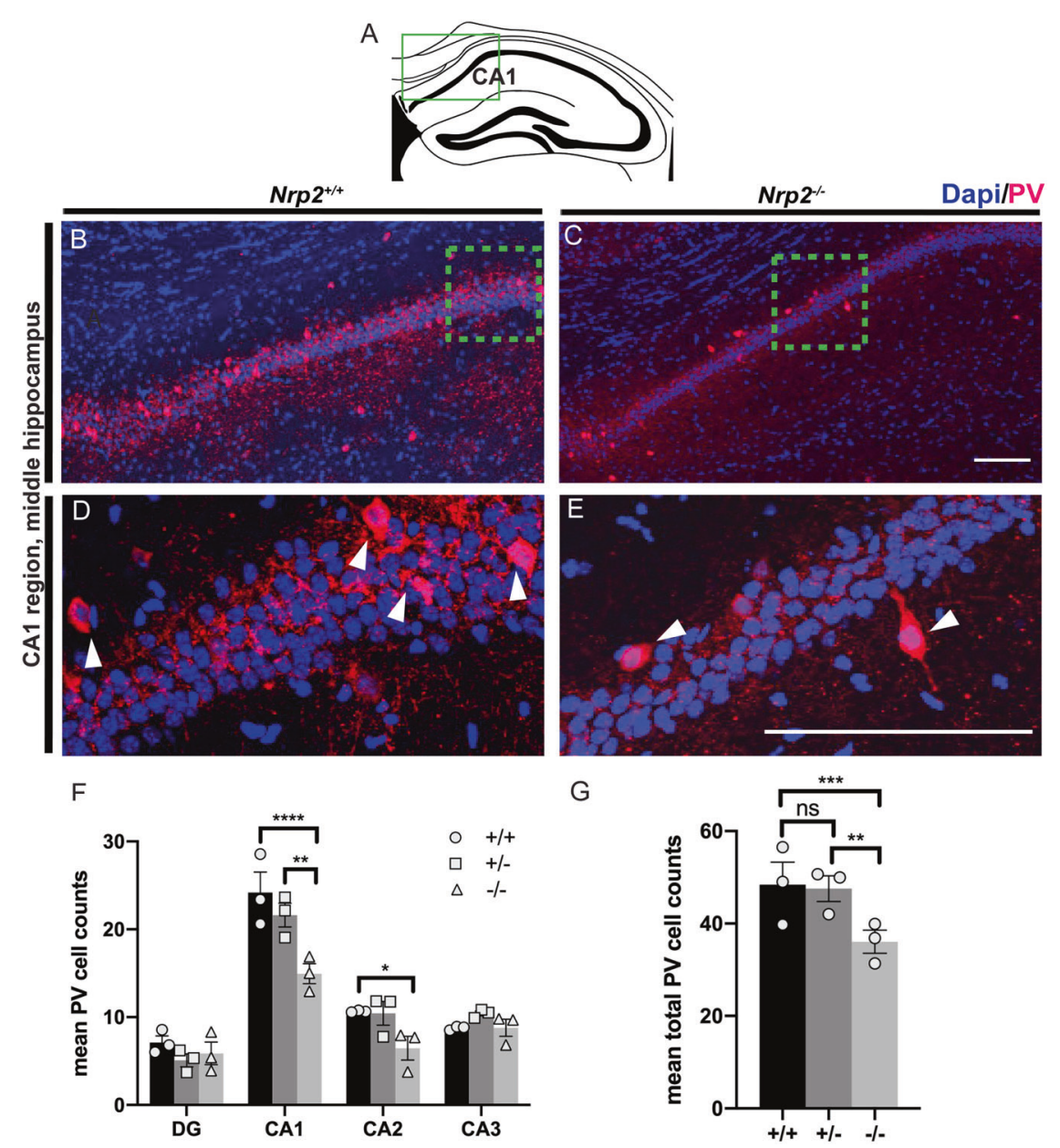

Fig. 1 Developmental deletion of Nrp2 leads to reduced numbers of parvalbumin (PV) expressing neurons in the CA1 region of the hippocampus. A Schematic of a coronal adult hippocampal section, green box indicates CA1 hippocampal region of images in B-E. B-C Immuno-labeled of $\mathrm{Nrp2}^{+/+}$(littermate control) and $\mathrm{Nrp}^{-/-}$brain sections, respectively, with anti-PV (red) and DAPI (blue). D-E High magnification images of green boxes in B and C, respectively. Scale bars: $100 \mu \mathrm{m}$ in $\mathbf{C}$ and $\mathbf{E}$ for $\mathbf{B}$ and $\mathbf{D}$, respectively. $\mathbf{F}$ Quantification of the averaged number of PV + cells by hippocampal region. Significantly fewer number of PV + neurons found in CA1 region of $N r p 2^{-1-}$ compared to $\mathrm{Nrp}^{+/+}$mice. Error bars are $\pm \mathrm{SEM}$; two-way ANOVA, post hoc Tukey: ${ }^{* * * *} p<0.0001+/+$ vs. $-/-;{ }^{* *} p=0.0012+/-$ vs. $-/-$ in CA $1 ;{ }^{*} p=$ $0.0435+/+$ vs. $-/-$ in CA2. G Quantification of total mean PV + cells. Significantly more PV expressing neurons found in hippocampal region of $\mathrm{Nrp2}^{+/+}$and $\mathrm{Nrp2}^{+/-}$mice compared to $\mathrm{Nrp2}^{-/-}$mice. Error bars are $\pm \mathrm{SEM}$; two-way ANOVA, post hoc Tukey: ${ }^{* * *} p=0.0004+/+\mathrm{vs}$. $-/-$; ${ }^{* *} p=0.0048+/-$ vs. $-/-;$ ns $p=0.6072$. For $\mathrm{F}$ and $\mathrm{G}: n=3$ animals/genotype.

mutant animals. We found a 37.1 and $42.7 \%$ decrease in SOM+ neurons in CA1 and CA2, respectively, from $\mathrm{Nrp2}^{-1-}$ as compared to $\mathrm{Nrp2}^{+/+}$mice (Fig. $3 \mathrm{~A}, \mathrm{~B}, \mathrm{E}-\mathrm{L}, \mathrm{U}$; cell numbers in CA1: $38.35 \pm$ $2.75 \mathrm{Nrp2}^{+/+}, 38.06 \pm 3.12 \mathrm{Nrp2}^{+/-}, 24.12 \pm 0.77 \mathrm{Nrp2}^{-/-} ; F_{(2,24)}=$ 41.26 two-way ANOVA with Tukey's multiple comparison correction $p<0.0001$; cell numbers in CA2: $17.71 \pm 0.24 \mathrm{Nrp2}^{+/+}, 13.06 \pm$ $1.69 \mathrm{Nrp2}^{+/-}, 10.15 \pm 0.85 \mathrm{Nrp2}^{-/-} ; F_{(2,24)}=41.26$ two-way ANOVA with Tukey's multiple comparison correction $p=0.0193$ ). We see an even larger reduction of SOM+ neuron in both the CA3 (Fig. 3C, M-P) and dentate gyrus (Fig. 3D, Q-T) at a 61.2 and $54.2 \%$ loss in $\mathrm{Nrp2}^{-/-}$as compared to $\mathrm{Nrp2} 2^{+/+}$mice, respectively (Fig. $3 \mathrm{U}$; cell numbers in CA3: $23.55 \pm 1.20 \mathrm{Nrp2}^{+/+}, 17.29 \pm 2.82 \mathrm{Nrp2}^{+/-}$, $9.13 \pm 0.59 \mathrm{Nrp2}^{-1-} ; F_{(2,24)}=41.26$ two-way ANOVA with Tukey's multiple comparison correction $p=0.0001$; cell numbers in DG: $18.65 \pm 1.54 \mathrm{Nrp2}^{+/+}, 12.90 \pm 2.28 \mathrm{Nrp2}^{+/-}, 8.53 \pm 1.04 \mathrm{Nrp2}^{-/-}$; $F_{(2,24)}=41.26$ two-way ANOVA with Tukey's multiple comparison correction $p=0.0018$ ). The overall decrease in SOM + neurons (Fig. 3V; total mean cell number: $98.26 \pm 2.06 ~ N r p 2^{+/+}, 81.31 \pm 9.29$ $\mathrm{Nrp2} 2^{+/-}, 51.93 \pm 2.39 \mathrm{Nrp2}^{-/-} ; F_{(2,24)}=41.26$ two-way ANOVA with Tukey's multiple comparison correction $p<0.0001$ for $\mathrm{Nrp2}^{-1-}$ vs. $\mathrm{Nrp2} 2^{+/+}, p=0.0085$ for $\mathrm{Nrp2}^{+/-}$vs. $\mathrm{Nrp2}^{+/+}$) was $47.2 \%$ in all hippocampal regions in $\mathrm{Nrp2}^{-/-}$as compared to $\mathrm{Nrp2} 2^{+/+}$, with a smaller but significant reduction of $17.2 \%$ between $\mathrm{Nrp2}^{+/-}$vs. $\mathrm{Nrp2}^{+/+}$animals. Together, we find that all three major interneurons populations, $\mathrm{PV}+, \mathrm{NPY}+$ and $\mathrm{SOM}+$, are significantly reduced in the CA1 of $\mathrm{Nrp2}^{-/-}$mice as compared to $\mathrm{Nrp2}^{+/+}$ controls. This finding is in contrast to a previous report showing the majority of the interneuron loss in the NPY + population and a slight reduction in $\mathrm{PV}+$ neurons in CA1 and CA3 with no loss of SOM + neurons [19]. Furthermore, we demonstrate that SOM + neurons show the greatest decrease in all hippocampal subfields.

\section{Synaptic Inhibition is reduced in mice lacking Nrp2}

In light of the marked decrease in all three interneuronal classes in hippocampal CA1 of $\mathrm{Nrp}^{-/-}$mice, we examined whether the deletion of Nrp2 alters synaptic inhibitory inputs to CA1 pyramidal cells (Fig. 4A-D). In voltage clamp recordings from CA1 pyramidal cells, the frequency of sIPSCs in Nrp2-deficient mice was significantly reduced compared to $\mathrm{Nrp2}^{+/+}$littermates but was not different between $\mathrm{Nrp2}^{+-}$and $\mathrm{Nrp2}^{-/-}$mice (Fig. 4C: frequency in $\mathrm{Hz}$, $\mathrm{Nrp2}^{+/+}: 23.91 \pm 2.30$, median $=24.41, \mathrm{IQR}=6.37-30.12, \quad n=12$ cells/ 4 mice; $\mathrm{Nrp2}^{+-}$: $16.45 \pm 2.44, \quad$ median $=8.83, \quad \mathrm{IQR}=$ 3.378-20.33, $n=13$ cells/ 4 mice; $N r p 2^{-/-}: 17.57 \pm 1.32$, median $=$ $8.753, \mathrm{IQR}=4.089-30.192, n=19$ cells/ 5 mice; $p<0.05, \mathrm{~K}-\mathrm{S}$ test). 


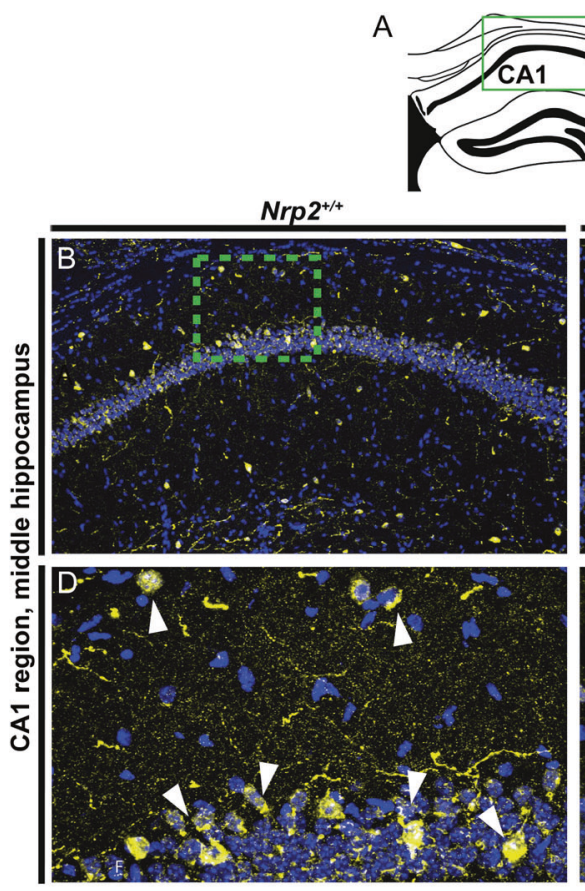

F

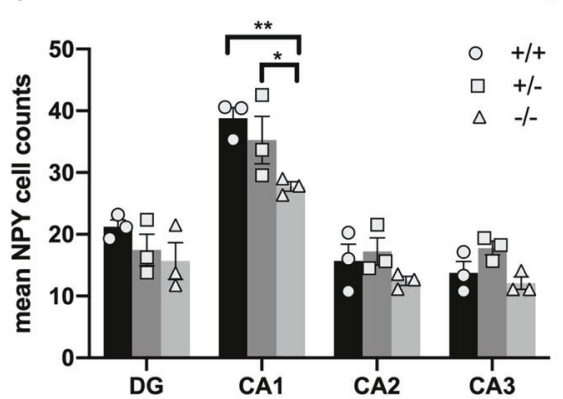

G

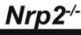
Dapi/NPY
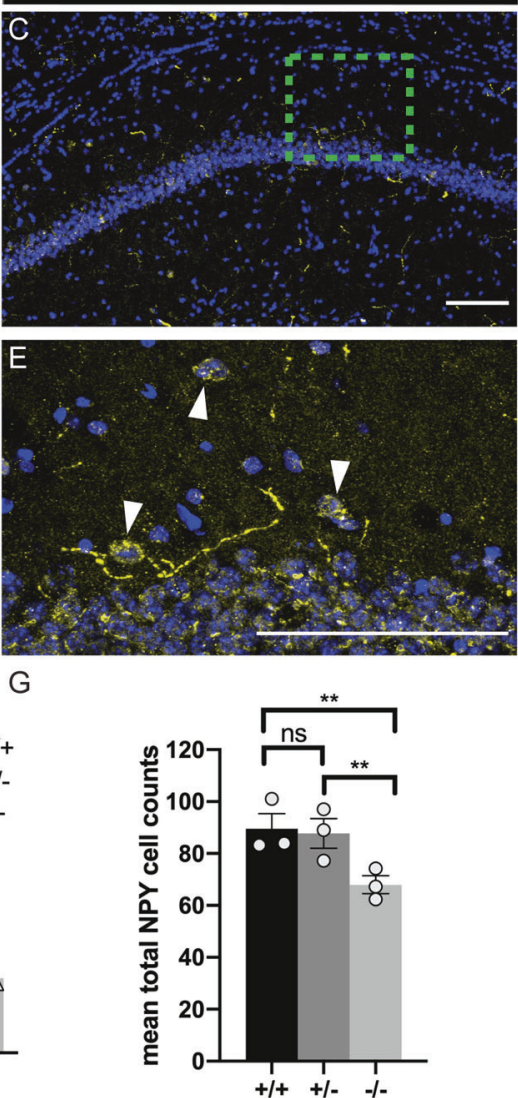

Fig. 2 Nrp2 deletion results in reduced numbers of neuropeptide $\mathrm{Y}$ (NPY) expressing neurons in the CA1 region. A Schematic of a coronal adult hippocampal section, green box indicates CA1 hippocampal region of images in (B-E). B-C Immuno-labeled $\mathrm{Nrp2}^{+/+}$and $\mathrm{Nrp2} 2^{-/-}$brain sections, respectively, with anti-NPY (yellow) and Dapi (blue). D and E High magnification images of green boxes in B and C, respectively, with white arrows indicating cells. Scale bars: $100 \mu \mathrm{m}$ in C and E for B and D, respectively. F Quantification of the averaged number of NPY + cells by hippocampal region. Significantly more NPY + neurons found in CA1 region of $\mathrm{Nrp2}^{+/+}$compared to Nrp2 ${ }^{-1-}$ mice. Error bars are \pm SEM; twoway ANOVA, post hoc Tukey: ${ }^{*} p=0.0474,{ }^{* *} p=0.0030$. G Quantification of total mean NPY + cells. Significantly fewer NPY expressing neurons found in hippocampal region of $\mathrm{Nrp2}^{-/-}$compared to $\mathrm{Nrp2}^{+/+}$or $\mathrm{Nrp2} 2^{+/-}$mice. Error bars are $\pm \mathrm{SEM}$; two-way ANOVA, post hoc Tukey: ${ }^{* *} p=$ $0.0040+/+$ vs. $-/-,{ }^{* *} p=0.0078+/-$ vs. $-/-$, and $\mathrm{ns} p=0.9569$. In F and G: $n=3$ animals/genotype.

Similarly, sIPSC amplitude was also reduced in $\mathrm{Nrp2}^{-1-}$ mice (Fig. 4D: amplitude in $\mathrm{pA}, \mathrm{Nrp2}^{+/+}: 30.81 \pm 2.74$, median $=32.16, \mathrm{IQR}=$ 25.08-44.72, $n=12 ; \mathrm{Nrp2}^{+/}:$: 28.39 \pm 1.74 , median $=29.26, \mathrm{IQR}=$ 23.91-39.13, $n=13 ; \mathrm{Nrp2}^{-1-}: 28.52 \pm 2.35$, median $=30.05, \mathrm{IQR}=$ 24.51-40.74, $n=19 ; p<0.05, \mathrm{~K}-\mathrm{S}$ test). Thus, consistent with the reduction in interneuron populations, spontaneous synaptic inhibitory inputs to CA1 pyramidal neurons is also significantly decreased in $\mathrm{Nrp2}^{-1-}$ mice. It is notable that while the apparent reduction in $\mathrm{PV}+$ and NPY + interneuron numbers in mice heterozygous for Nrp2 deletion failed to reach statistical significance (Figs. 1-2), $\mathrm{Nrp2}^{+/-}$mice received fewer sIPSCs than littermate $\mathrm{Nrp} 2^{+/+}$mice demonstrating reduced functional inhibition.

\section{Nrp2 deletion alters intrinsic physiology of CA1 Pyramidal Neurons}

We next sought to determine whether deletion of Nrp2 signaling and the ensuing network reorganization impacts intrinsic active and passive properties of CA1 Pyramidal cells. Analysis of the voltage responses to graded current injections from a holding potential of $-60 \mathrm{mV}$ revealed a consistent reduction in frequency of action potential firing in CA1 pyramidal cells from $\mathrm{Nrp2}^{+/-}$and $\mathrm{Nrp2}^{-/-}$ mice compared to age-matched $\mathrm{Nrp2}^{+/+}$littermates (Fig. $5, n=17$ cells $/ 4 \mathrm{Nrp2}^{+/+}$mice, 11 cells from $4 \mathrm{Nrp2}^{+/-}$mice and 13 cells from $5 \mathrm{Nrp2}^{-}$mice). Additionally, there was an increase in action potential amplitude in $\mathrm{Nrp2}^{+/-}$and $\mathrm{Nrp2}^{-/-}$relative to $\mathrm{Nrp2}^{+/+}$(Fig. 5C: action potential amplitude in $\mathrm{mV}, \mathrm{Nrp2}^{+/+}: 73.50 \pm$ 2.00, $\mathrm{n}=16 \quad$ cells $/ 4$ mice; $\quad N r p 2^{+/-}: \quad 83.23 \pm 1.64$, $n=10$ cells/4 mice; Nrp2 ${ }^{-/-}: 85.82 \pm 1.58, n=11$ cells $/ 5$ mice; $p=$ $0.001, F_{(1,36)}=13.167, \mathrm{DF}=36$, One-way ANOVA). There was an apparent increase in spike frequency adaptation ratio in $\mathrm{Nrp2}^{+/-}$and $\mathrm{Nrp2} 2^{-/-}$mice, which failed to reach statistical significance (Fig. 5D: spike adaptation ratio, $\mathrm{Nrp2}^{+/+}: 0.52 \pm 0.05, n=16 ; \mathrm{Nrp2}^{+/-}: 0.63 \pm$ $0.07, n=8 ; N r p 2^{-/-}: 0.65 \pm 0.06 \mathrm{mV}, n=13 ; p=0.193$, One-way ANOVA). Examination of passive properties revealed that the resting membrane potential in pyramidal cells from mice lacking Nrp2 was hyperpolarized relative to $\mathrm{Nrp2}^{+/+}$mice (Fig. 5E: resting membrane potential in $\mathrm{mV}, \mathrm{Nrp2}^{+/+}:-61.12 \pm-0.82, n=17 ; \mathrm{Nrp2}^{+/-}:-65.40 \pm$ $-1.25, n=11 ; \mathrm{Nrp2}^{-1-}$ : $-64.57 \pm-0.75, n=13 ; 0.004, F=16.388$, $\mathrm{DF}=40$, One-way ANOVA). However, the input resistance was not different between groups (Fig. $5 \mathrm{~F}: \mathrm{R}_{\text {in }}$ in $\mathrm{M} \Omega, N r p 2^{+/+}: 203.23 \pm 16.73$, $\mathrm{n}=17 ; \mathrm{Nrp2}^{+/-}: 178.63 \pm 12.94, n=11 ; \mathrm{Nrp2}^{-/-}: 174.74 \pm 12.23, n=$ $13 ; p=0.481, h=1.462$ with $2 \mathrm{DF}$, ANOVA on Ranks). Similarly, the 


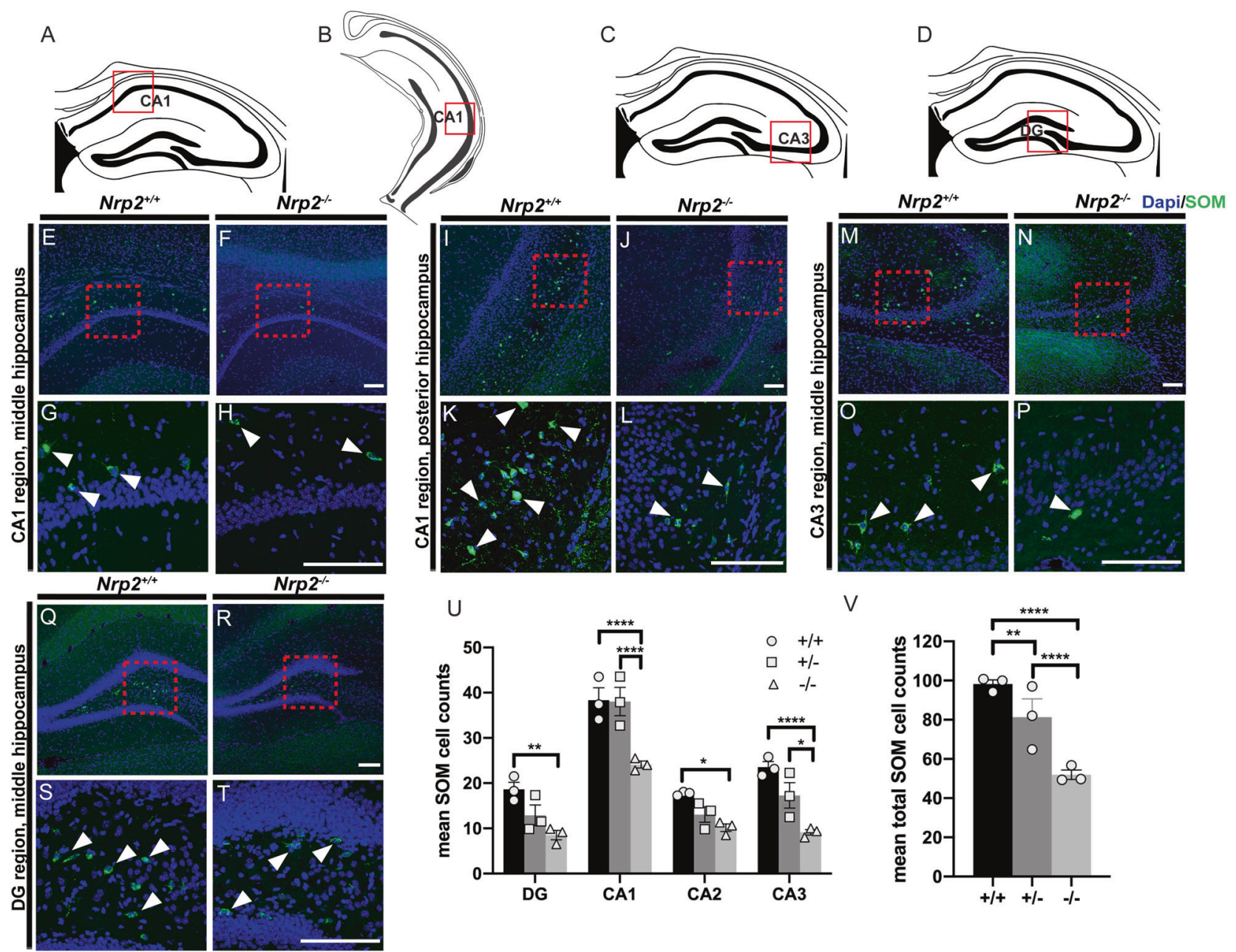

Fig. 3 Somatostatin (SOM) expressing interneurons in all hippocampal subregions are significantly fewer in number in $\mathrm{Nrp2}^{-/}$ compared to wild type $\left(\mathbf{N r p 2}^{+/+}\right)$. A-B Schematics show coronal adult sections of the CA1 region in the middle and posterior hippocampus, respectively. Red box in $\mathbf{A}$ and $\mathbf{B}$ indicates the CA1 region illustrated by images in E-H and I-L, respectively. C-D Schematics of coronal adult sections in the middle hippocampus, red boxes indicate the CA3 and DG region of images in $\mathbf{M}-\mathbf{P}$ and $\mathbf{Q}-\mathbf{T}$, respectively. E-H Immuno-labeled of littermates $\mathrm{Nrp2}^{+/+}(\mathbf{E}, \mathbf{G})$ and $\mathrm{Nrp2}^{-/-}(\mathbf{F}, \mathbf{H})$ sections with anti-SOM (green) and Dapi (blue) in the middle CA1 region. Red boxes in $\mathbf{E}$ and $\mathbf{F}$ are the locations of the high magnification images shown in $\mathbf{G}$ and $\mathbf{H}$, respectively. I-L Immuno-labeled of littermates $\mathrm{Nrp2}^{+/+}(\mathbf{I}, \mathbf{K})$ and $\mathrm{Nrp2}^{-/-}(\mathbf{J}$, L) sections with anti-SOM (green) and Dapi (blue) in the posterior CA1 region. Red boxes in I and J are the locations of the high magnificent images shown in $\mathrm{K}$ and L, respectively. M-P Immuno-labeled sections from littermates $\mathrm{Nrp2}^{+/+}(\mathbf{M}, \mathbf{0})$ and $\mathrm{Nrp2}^{-1-}(\mathbf{N}, \mathbf{P})$ with anti-SOM (green) and Dapi (blue) in the CA3 region. Red boxes in $\mathrm{M}$ and $\mathbf{N}$ show the location of high magnification images in $\mathbf{O}$ and $\mathbf{P}$, respectively. $\mathbf{Q}-\mathbf{T}$ Littermates $\mathrm{Nrp2}^{+/+}(\mathbf{Q}, \mathbf{S})$ and $\mathrm{Nrp2}^{-1-}(\mathbf{R}, \mathbf{T})$ sections are immuno-labeled with anti-SOM (green) and Dapi (blue) in the DG region. Red boxes in Q and R show the location of high magnification images in $\mathbf{S}$ and T, respectively. Scale bars: $100 \mu \mathrm{m}$ in $\mathbf{F}, \mathbf{J}, \mathbf{N}$, and $\mathbf{R}$ for $\mathbf{E}-\mathbf{F}, \mathbf{I}-\mathbf{J}, \mathbf{M}-\mathbf{N}$, and $\mathbf{Q}-\mathbf{R}$, respectively; $100 \mu \mathrm{m}$ in $\mathbf{H}, \mathbf{L}, \mathbf{P}$, and T for G-H, K-L, O-P, and S-T, respectively. U) Quantification of the averaged number of SOM + cells by hippocampal region. Significantly fewer number of SOM + neurons found in CA1, CA2, CA3, and DG regions of Nrp2 ${ }^{-/-}$compared to Nrp2 ${ }^{+/+}$mice. Error bars are \pm SEM; two-way ANOVA, post hoc Tukey: ${ }^{* *} p=0.0018+/+$ vs. $-/-$ in DG; ${ }^{* * * *} p<0.0001+/+$ vs. $-/-$ and $+/-$ vs. $-/-$ in CA1; ${ }^{*} p=0.0193+/+$ vs. $-/-$ in CA2; ${ }^{* * * *} p<0.0001+/+$ vs. $-/-,{ }^{*} p=0.0113+/-$ vs. $-/-$ in CA3. V) Quantification of total mean SOM + cells. Significantly fewer SOM + expressing neurons overall found in the hippocampus of $\mathrm{Nrp2}^{+--}$and $\mathrm{Nrp2}^{-1-}$ as compared to $\mathrm{Nrp2} 2^{+++}$mice. Error bars are $\pm \mathrm{SEM}$; two-way ANOVA, post hoc Tukey: ${ }^{* * *} p<0.0001+/+$ vs. $-I-$ and $+/-$ vs. $-I-;{ }^{* *} p=0.0085+/+$ vs. $+/-$. For $U$ and V, $n=3$ animals/genotype.

sag ratio, which is a measure of $h$-currents, was not different between groups (Fig. 5G: Sag ratio, $\mathrm{Nrp2}^{+/+}: 0.84 \pm 0.01, n=12 ; \mathrm{Nrp2} 2^{+/-}$: $0.84 \pm 0.01, n=10 ; \mathrm{Nrp2}^{-1-}: 0.84 \pm 0.01, n=13 ; p=0.927, \quad F=$ $0.0765, \mathrm{DF}=34$, One-way ANOVA). Together the reduction in firing frequency and hyperpolarized resting potential both suggest that CA1 pyramidal cell excitability is reduced in both $\mathrm{Nrp2}^{+/-}$and $\mathrm{Nrp2} 2^{--}$mice when compared to $\mathrm{Nrp2}^{+/+}$mice.

\section{Nrp2 deletion accelerates development of Kainic acid (KA) induced seizures}

To evaluate the impact of Nrp2 deletion and the resulting complementary changes of reduced inhibition and pyramidal cell- intrinsic excitability on global hippocampal network excitability, mice were implanted with hippocampal depth electrode and injected with a single convulsive dose of $\mathrm{KA}(25 \mathrm{mg} / \mathrm{kg})$ to examine the development of seizures. No spontaneous seizures were observed during handling and baseline recordings prior to KA injection did not show evidence of interictal or epileptiform activity. $\mathrm{Nrp} 2^{-1-}$ mice exhibited a significantly shorter latency to convulsive seizures as compared to $\mathrm{Nrp2}^{+/+}$mice (Fig. 6D, Latency in min: $\mathrm{Nrp2}^{-/-}: 4.68 \pm 1.25$, median: 4.30, IQR: 3.22-5.34, $n=5$; $N r p 2^{+/-}: 16.83 \pm 3.91$, median: 14.83, IQR: $10.1-18.8, n=6$ and $\mathrm{Nrp2}^{+/+}: 32.23 \pm 7.87$, median: 30.25 , IQR: $18-36.4, n=6, p<0.01$ for $\mathrm{Nrp2}^{-/-}$vs. Nrp2 ${ }^{+/+}$, Kruskal-Wallis Rank-Sum Test followed by 

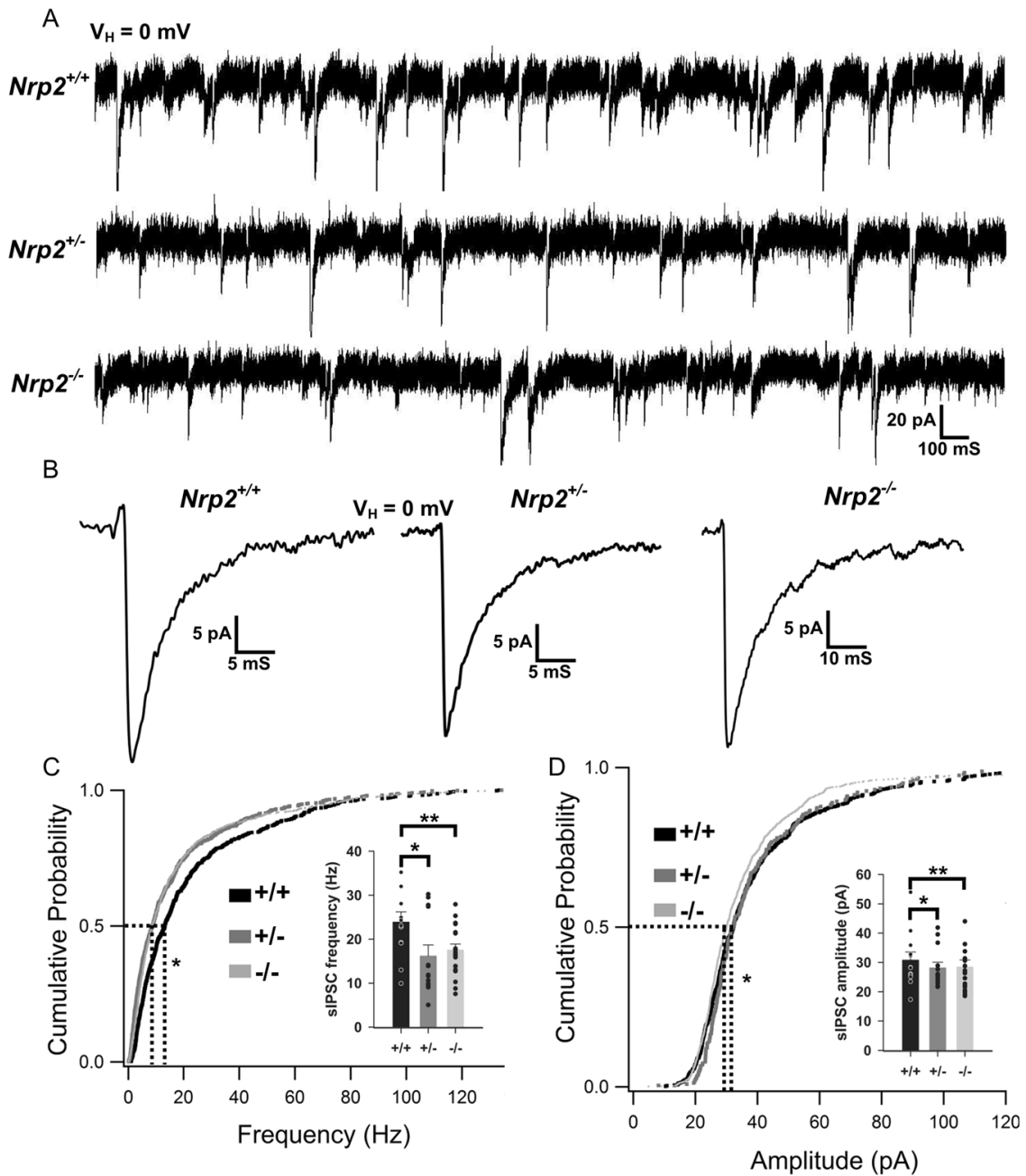

Fig. 4 Differences in pyramidal cells sIPSC frequency and amplitude between Nrp2 knockouts, heterozygotes and wild-type littermates. A Representative sIPSC traces from CA1 pyramidal cells of $\mathrm{Nrp2}^{+/+}, \mathrm{Nrp2}^{+/-}$and $\mathrm{Nrp2}^{-/-}$. B Representative average sIPSC traces from the three groups. C Cumulative Probability plots for frequency of sIPSCs in $\mathrm{Nrp2}^{+/+}(\mathbf{n}=12), \mathrm{Nrp2}^{+/-}(\mathbf{n}=13)$ and $\mathrm{Nrp2}^{-/-}(n=19)$. Inset, summary bar plot showing the frequency of sIPSCs from the three genotypes. D Cumulative Probability plots for amplitude of sIPSCs in Nrp2 ${ }^{+/+}(n=12)$, $\mathrm{Nrp2}^{+/-}(n=15)$ and $\mathrm{Nrp2} 2^{-/-}(n=19) .{ }^{*}$ indicates $p<0.05$ by Kolmogorov-Smirnov test.

pairwise comparison with Dunn's test). While the seizure latency in $\mathrm{Nrp2} 2^{+/-}$mice trended to be lower than in $\mathrm{Nrp2}^{+/+}$mice the difference did not reach statistical significance. Similarly, the total duration of seizure activity measured in the first 30 min after KA injections was significantly longer in $\mathrm{Nrp}^{-1-}$ mice as compared to $\mathrm{Nrp2} 2^{+/+}$mice while the seizure duration in $\mathrm{Nrp2}^{+/-}$mice was not different from $\mathrm{Nrp2}^{+/+}$mice (Fig. $6 \mathrm{E}$, Time in minutes: $\mathrm{Nrp2}^{-1-}$ : $7.19 \pm 0.73, n=4 ; \mathrm{Nrp2}^{+/-}: 3.08 \pm 0.98, n=5$ and $\mathrm{Nrp2}^{+/+}: 2.50 \pm$ $1.28, n=5, p<0.05$ for $\mathrm{Nrp2}^{-/-}$vs. Nrp2 ${ }^{+/+} ; p=0.05$ for $\mathrm{Nrp2} 2^{-/-}$ vs. Nrp2 $2^{+/-}, \mathrm{F}_{(2,11)}=5.29$, one-way ANOVA followed by pairwise comparison with Tukey's test). The severity of behavioral seizures, scored based on the modified Racine's scale (see methods), was also greater in $\mathrm{Nrp2}^{-/-}$with four out of five mice reaching a Racine score of 5 within 10 min of KA injection while one out of five $\mathrm{Nrp2}^{+/-}$mice and none of the $\mathrm{Nrp2} 2^{+/+}$reached a Racine scale of 5 during the same period. The cumulative seizure score in the first $30 \mathrm{~min}$ post $\mathrm{KA}$ injection showed that $\mathrm{Nrp2}^{-1-}$ mice had significantly higher convulsive seizures compared to $\mathrm{Nrp2}^{+/+}$ mice. Nevertheless, the difference between $\mathrm{Nrp2}^{-1-}$ mice and $\mathrm{Nrp2}^{+/-}$mice failed to reach statistical significance (Fig. 6C: $\mathrm{Nrp2}^{-1-}$ : $23.4 \pm 1.44$, median: 25, IQR: $21-26, n=5 ; \mathrm{Nrp2}^{+/-}: 13.3 \pm 2.17$, median: 12.5, IQR: $11.2-13.8, n=6$ and Nrp2 ${ }^{+/+}: 9.3 \pm 3$, median: 7.5, IQR: $4.5-10.5, n=6, p<0.01$ for $\mathrm{Nrp2}^{-/-}$vs. $\mathrm{Nrp2} 2^{+/+}$,
Kruskal-Wallis Rank-Sum Test followed by pairwise comparison with Dunn's test. Together these data reveal that $\mathrm{Nrp2}^{-1-}$ mice exhibit increases susceptibility and greater severity of electrographic and behavioral seizures as compared to $\mathrm{Nrp2}^{+/+}$mice.

\section{Loss of Nrp2 reduces cognitive flexibility in an operant reversal-learning task}

One of the hallmarks of ASD-associated behaviors is repetitive behavior [45], which has been suggested as result of "extreme" habit formation and inability to flexibly execute goal-directed actions [46]. To evaluate how loss of Nrp2 affects cognitive flexibility, we examined the performance of mice on an operant reversal-learning task (Fig. 7A). All mice ( $5 \mathrm{Nrp2}^{-/-}, 5 \mathrm{Nrp2}^{+/-}$, and $5 \mathrm{Nrp2}^{+/+}$) learned to make an operant response for food rewards; however, during the reversal task $\mathrm{Nrp2}^{-/-}$and $\mathrm{Nrp2}^{+/-}$mice diverged from controls in their responses following loss trials. $\mathrm{Nrp2}{ }^{-/-}$and $\mathrm{Nrp2}^{+/-}$mice showed a significantly reduced loseshift ratio compared to $N r p 2^{+/+}$mice (Fig. 7B; ANOVA $F_{(2,12)}=5.25$, $p=0.0230$ followed by Tukey's test for multiple comparisons: $p=$ $0.0320 \mathrm{Nrp2}^{+/+}$vs. $\mathrm{Nrp2}^{-/-} ; p=0.0496 \mathrm{Nrp2}^{+/+}$vs. $\mathrm{Nrp2}^{+/-}$). Data for each subject represent the mean lose-shift ratio over 15 test sessions. We observed no difference between groups in responses on trials following a reward, as shown by no significant difference 

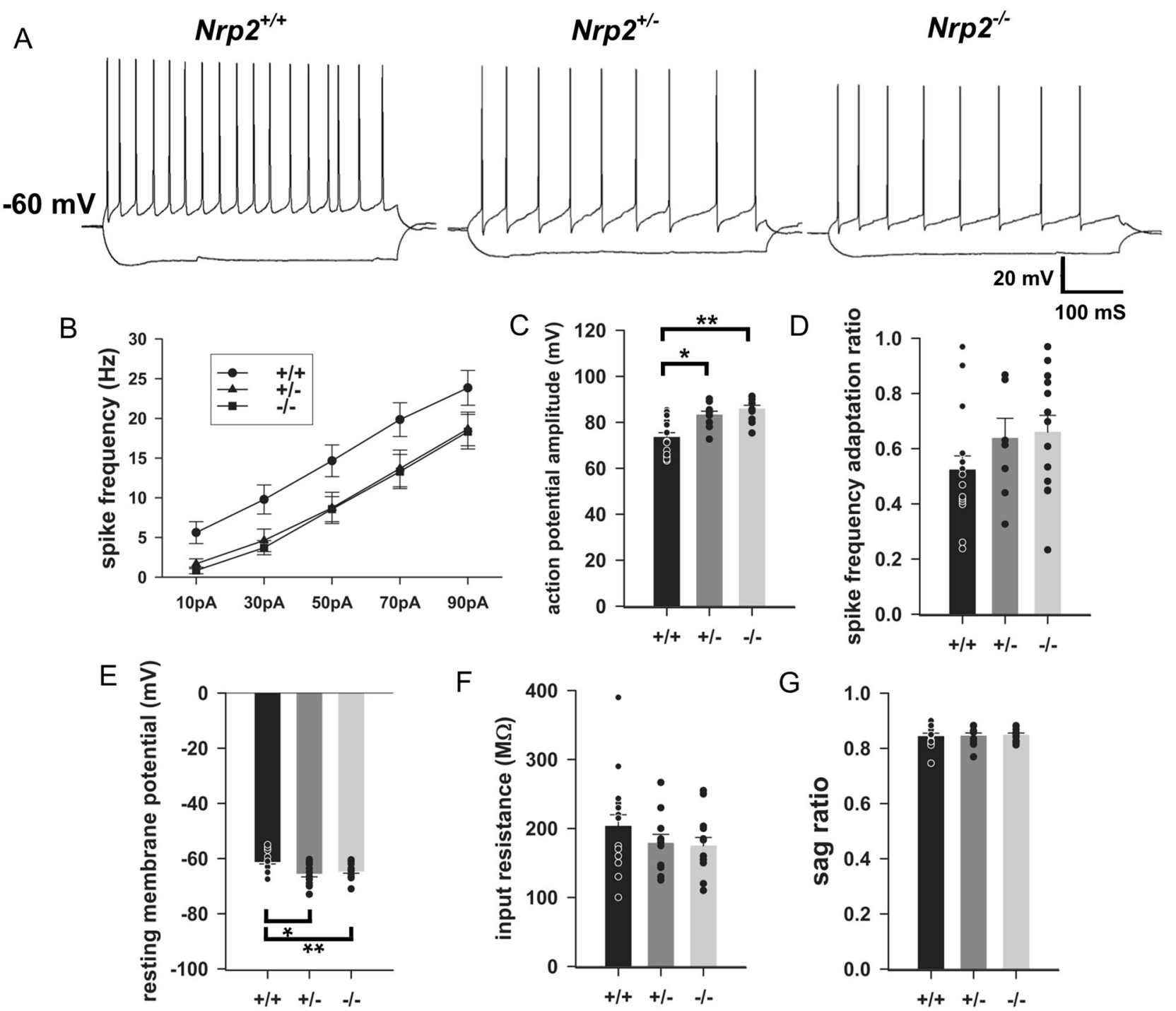

Fig. 5 Pyramidal cells intrinsic physiology is altered by Nrp2 deletion. A Representative current-voltage traces from $\mathrm{Nrp2} 2^{+/+}$(left), $\mathrm{Nrp2} 2^{+/-}$ (middle) and $\mathrm{Nrp2}^{-1-}$ (right) CA1 pyramidal cells. B I/F curve showing the frequencies of firing in response to 10-90 pA current injection in $\mathrm{Nrp2}^{+/+}(n=17), \mathrm{Nrp2}^{+/-}(n=11)$, and $\mathrm{Nrp2}^{-1-}(n=13)$. Significant effect of genotype $F_{(2,38)}=4.006, p=0.026$ by two-way repeated measures ANOVA and $p<0.05$ for pairwise comparison $\mathrm{Nrp2}^{+/+}$and $\mathrm{Nrp2}^{-/-}$using Holm-Sidak method. C-G Summary plots of Action Potential Amplitude (C) Spike Frequency Adaptation Ratios (D), Resting Membrane Potential (E), Input Resistance (F), and Sag Ratio (G). $n=16-17$ for $\mathrm{Nrp2}^{+/+}, 8-11$ for $\mathrm{Nrp2}^{+-}$and 11-13 for $\mathrm{Nrp2}^{-/-}$. ${ }^{*}$ indicates $p<0.05$ one-way ANOVA followed by pairwise comparison using Holm-Sidak method. Data presented as mean \pm sem.

in the win-stay ratio (Fig. 7C; $p>0.3$ for all comparisons). Additionally, Nrp2-deficient mice completed a similar number of trials per session as control mice (average trials per session \pm SEM: $\mathrm{Nrp2} 2^{-/-}=76.04 \pm 2.6 ; \mathrm{Nrp2}^{+/+}=74.85 \pm 4.5 ; \mathrm{Nrp}^{+/-}=75.25 \pm$ 4.4). The duration to complete a session did not differ between genotypes (average number of minutes to complete a session \pm SEM: Nrp2 $\left.2^{-/-}=21 \pm 1.7 ; \mathrm{Nrp}^{+/+}=20 \pm 3.1 ; \mathrm{Nrp2}^{+/-}=19 \pm 2.8\right)$. These data suggest that basic appetitive motivational and reward processes were intact in Nrp2-deficient mice. Rather, the inability to shift responses after a loss trial from the $\mathrm{Nrp2}^{-/-}$animals is indicative of behavioral inflexibility.

\section{DISCUSSION}

It is well established that alterations in GABAergic circuits impact a wide variety of neurobiological functions leading to neurological disorders, including the highly comorbid conditions of ASD and epileptic seizures [1, 17,47]. However, the contribution of perturbations in different classes of GABAergic interneurons to the pathophysiological mechanisms and the associated behavioral phenotypes observed in autism and epilepsy is not well understood. In our study, we investigated a loss-of-function genetic mouse model, specifically targeted to the Nrp2 locus, which has known mutations linked to autistic patients [22, 23], to determine the cellular, physiological and behavioral aspects of Nrp2's contribution to epileptic seizures and ASD-like phenotypes when single versus double copies of Nrp2 is deleted. We demonstrated that Nrp2 is required for appropriate maturation of synaptic inhibition and regulates the density of multiple hippocampal interneuron types; largely reducing SOM+cell numbers in all CA subregions and DG of the hippocampus. We also showed that both Nrp2 heterozygous and homozygous mutants have reduced intrinsic excitability of CA1 pyramidal neurons, which could indicate an innate compensatory mechanism to restrain excessive excitation in the presence of reduced synaptic inhibition and interneuron numbers. We identified that the loss of diverse interneuron classes, which support inhibition across multiple dendritic zones [43], was associated with increase 


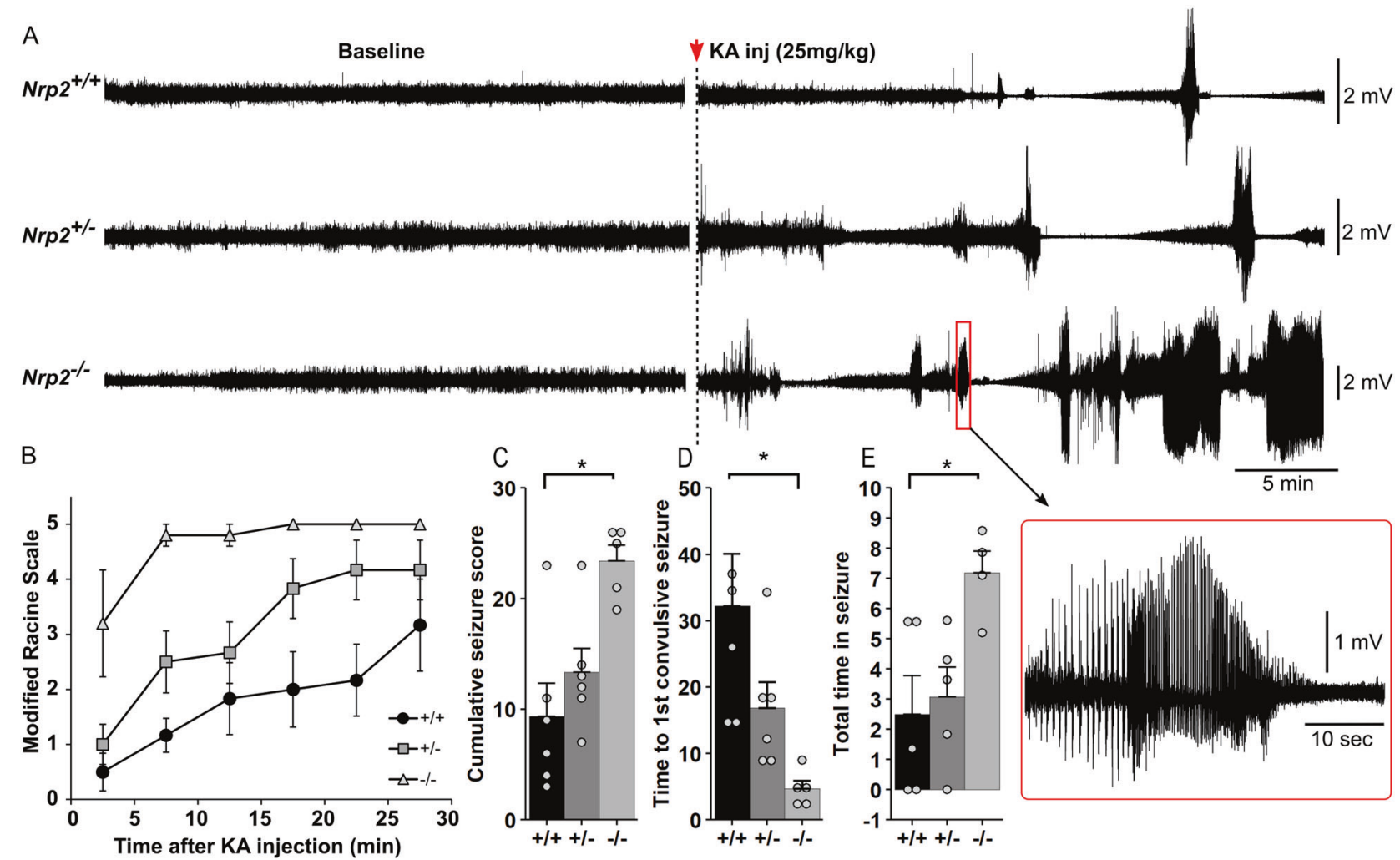

Fig. 6 Increased susceptibility to chemically induced seizures in mice lacking Nrp2. A Representative baseline EEG traces (left) and EEG traces following KA injection (right) show development of electrographic seizures in Nrp2 ${ }^{+/+}$(top), Nrp2 ${ }^{+/-}$(middle), and Nrp2 ${ }^{-/-}$(bottom) mice during the first $30 \mathrm{~min}$ following injection of Kainic acid $(25 \mathrm{mg} / \mathrm{kg})$. B Latency to first convulsive seizure following KA inj. Note that $N r p 2^{-/-}$mice $(n=5)$ develop convulsive seizures significantly faster than $\mathrm{Nrp2}^{+/-}(n=6), \mathrm{Nrp2}^{+/+}(n=6)$ mice. C Cumulative seizures score indicates severity of behavioral seizures scored using the modified Racine scale. D Time to first convulsive seizure following KA injection. *indicates $p<0.05$ by pairwise comparison using Dunn test, following Kruskal-Wallis rank-sum test $\mathbf{E}$ Total duration of electrographic seizures in the first $30 \mathrm{~min}$ after KA inj shows that that $\mathrm{Nrp2}^{-/-}$mice spend significantly longer duration seizing compared to $\mathrm{Nrp2} 2^{+/+}, \mathrm{Nrp2}{ }^{+/-}$mice. $^{-}$ *indicate $p<0.05$ by one-way ANOVA, post hoc Tukey's pairwise comparison.

susceptibility to kainic acid-induced seizures in the Nrp2 mutant animals as compared to littermate controls. Finally, we challenged the Nrp2 mutant mice in a reversal-learning task, which is used to measure cognitive flexibility [48]. The ability to make a flexible choice is often compromised in ASD individuals, who are frequently dominated by restrictive and repetitive behaviors [49]. There is increasing evidence that intact hippocampus circuit function is necessary to respond in an appropriately flexible manner, and disruptions render behavior habitual and inflexible $[50,51]$. Interestingly, both the $\mathrm{Nrp2}^{+/-}$and $\mathrm{Nrp2}^{-/-}$showed impaired cognitive flexibility as illustrated with significantly lower lose-shift ratios compared to $\mathrm{Nrp2}^{+/+}$control animals. Taken together, our findings provide novel insights into the cellular and physiological basis contributing to the behavioral phenotypes observed in heterozygous and homozygous Nrp2 mutant mice, and may serve as a useful model for studying the molecular mechanisms underlying developmental processes contributing the propensity for ASD and epilepsy comorbidity observed clinically.

\section{Impact of Nrp2 deletion on hippocampal inhibition and seizure susceptibility}

Our finding that global Nrp2 deletion causes significant decreases in three distinct interneuronal classes, $\mathrm{PV}+, \mathrm{SOM}+$, and NPY+ neurons in the hippocampal CA1 supports the role for Nrp2 in interneuron development [14, 42]. In particular, we found the most dramatic loss of SOM+ interneurons in all major hippocampal subfields, which previously have not been reported in the Nrp2 mutant animals. In contrast to prior reports [19], which only showed a selective PV + and NPY + cell number decrease in CA1. A previous study demonstrated that loss of Nrp2 in progenitor neurons from the $M G E$, which gives rise to the inhibitory interneurons that populate both the cortex and hippocampus, resulted in an increase in NPY+ interneurons in the striatum due to a migration defect [42]. Therefore, it is likely that the reduction in hippocampal interneuronal population following Nrp2 deletion, in our study, arises from the disruption of migration of interneuron precursors from the MGE during development. However, the decrease in the interneuron population identified here differs from the limited cell-specific depletion of NPY + neurons in $\mathrm{Nrp2}^{-/-}$ mice or lack of interneuron reduction in Sema3F knockout animals reported previously $[19,25]$. It is possible that methodological differences, particularly, age of the animals examined may underlie these differences in observations as migration of progenitors may still be an active process in younger animals. However, we cannot rule out a proliferation or differentiation defect, or an increase in apoptosis, as these cellular processes have not been examined in the Nrp2 mutant animals. Future investigations with neuronal birth dating experiments and apoptotic markers, beyond the scope of this study, will be required to confirm whether other cellular processes are disrupted in the Nrp2 mutant animals.

In keeping with the extensive interneuron loss, we find a significant reduction in the frequency of inhibitory synaptic inputs to CA1 pyramidal neurons in mice lacking Nrp2. Unlike the cell loss which was observed only in $N r p 2^{-1-}$ mice, the functional 
A

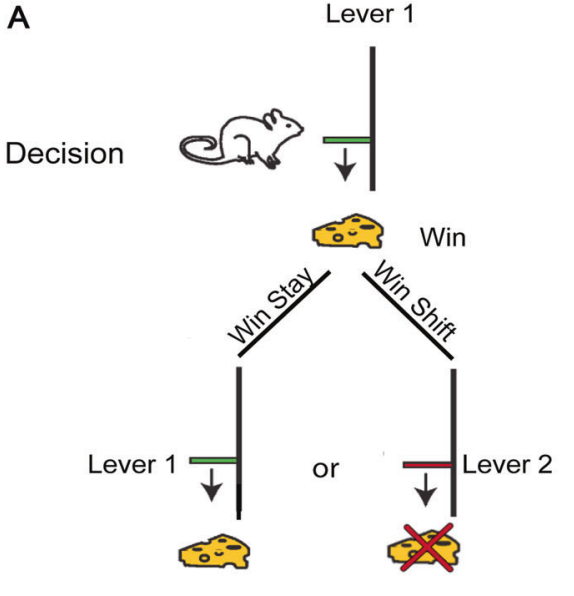

Lever 2

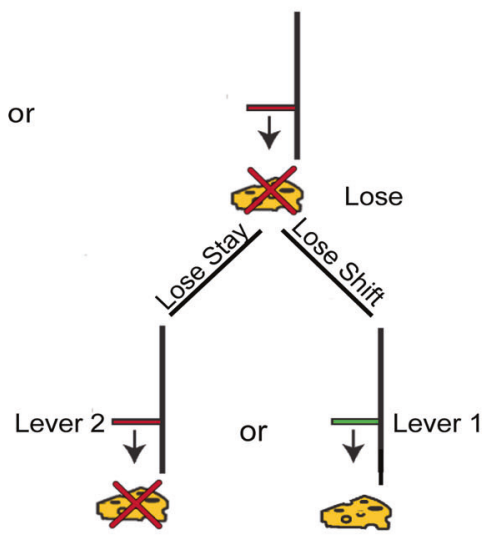

Earn 10 - 14 rewards then REVERSAL

B

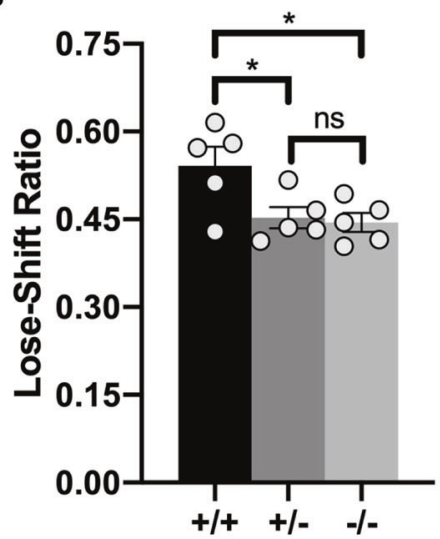

C

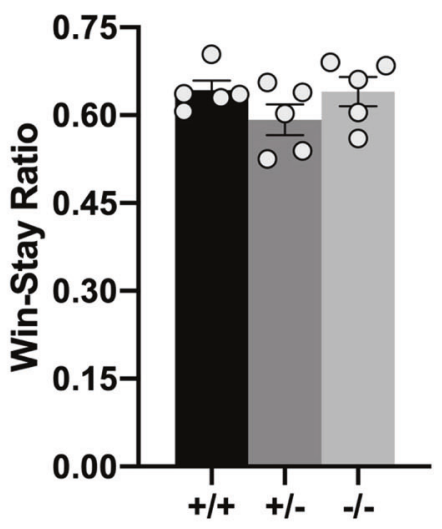

Fig. 7 Nrp2-deficient mice have impaired cognitive flexibility as seen in an operant reward-based reversal-learning task. A Schematic illustration of the reversal-learning task. Mice chose between two levers for a food reward. Responses on each trial were categorized as "win" or "loss" and "stay" or "shift" based on the previous trial's choice and outcome. B The lose-shift ratio was significantly reduced in Nrp2 ${ }^{-/-}$and $\mathrm{Nrp2}^{+/-}$compared to $\mathrm{Nrp2}^{+/+}$mice. C) No significant differences between genotypes were found for the win-stay ratio. Error bars are \pm SEM; one-way ANOVA, post hoc Tukey: ${ }^{*} p=0.0320+/+$ vs. $-/-,{ }^{*} p=0.0496+/+$ vs. $+/-$, and ns $p=0.9669, n=5$ animals/genotype.

reduction in inhibition was observed in $\mathrm{Nrp2}^{+/-}$littermates suggesting that, in addition to decrease in interneuron populations, circuit-level plasticity in Nrp2-deficient mice may also impair inhibition. In this regard, Nrp2 deletion is known to increase dendritic spines and excitatory inputs to glutamatergic neurons and regulate synapse formation and plasticity $[12,30]$. Our sIPSC recordings, conducted in glutamate receptor antagonists to limit the contribution of known changes in the excitatory inputs [30], identify that reducing Nrp2 signaling impairs basal inhibition. Interestingly, CA1 pyramidal neurons in Nrp2-deficient mice rest at more hyperpolarized potentials and have reduced firing in response to depolarizing current injections indicating that the changes in excitation inhibition (E/I) balance brought about by the increased excitatory drive $[30,35]$ and reduce inhibition (Fig. 4) may lead to compensatory metaplastic changes in intrinsic excitability. The reduction in resting membrane potential and excitability were not accompanied by changes sag ratio, a measure of h-currents, or input resistance and the channel mechanisms underlying these changes need further investigation. Despite the potential compensatory decrease in cell-intrinsic excitability, we find that the E/I imbalance reduces the latency to chemically induce seizures and increases seizure severity demonstrating increased epileptogenicity in $\mathrm{Nrp2}^{-/-}$mice. Although there were trends suggesting increased seizure susceptibility in $\mathrm{Nrp2}^{+/-}$mice, these did not reach statistical significance. The relative maintenance of interneuron numbers and seizure susceptibility in $\mathrm{Nrp2}^{+/-}$mice, despite impairments in intrinsic excitability, synaptic inhibition, and cognitive flexibility indicate some network-level compensation which, while sufficient to prevent epilepsy, may compromise finer cognitive processing.

\section{Hippocampal-dependent cognitive flexibility in ASD} phenotypic analysis

We assessed the ability of $\mathrm{Nrp2}^{+/+}, \mathrm{Nrp2}^{+/-}$, and $\mathrm{Nrp2}^{-/-}$mice to perform an operant reward-based deterministic reversal-learning task. In this task, mice use reinforcement history to guide their choice of actions. The optimal strategy is to choose the opposite lever following a nonrewarded "loss" trial and to repeat the same action after a rewarded "win" trial. We found that both the $\mathrm{Nrp2}^{+/-}$ and $\mathrm{Nrp2}^{-/-}$mice made fewer shifts to the opposite lever following a loss trial, as shown by a reduced lose-shift ratio compared to control mice. Rather, Nrp2-deficient mice continued to respond on the nonrewarded lever, which suggests an impairment in cognitive flexibility. Specifically, the repetition of nonrewarded responses following loss trials is a form of response perseveration, which is a well-known trait of autism [46]. In a previous study [20], we observed a similar form of response perseveration in Nrp2 null mice, in which mice displayed enhanced self-directed grooming. In contrast to responses following loss trials, Nrp2-deficient mice did not differ from 
controls in their responses following rewarded "win" trials, suggesting that basic appetitive motivational processes are not disturbed.

Cognitive inflexibility in reversal-learning tasks have also been shown in rats, Rhesus monkeys and humans following lesions of the hippocampus [50, 52-54]. In one study, faster reversal-learning rates were shown to be associated with an increased ratio of PV + interneurons to granule cells in the hippocampus [55]. Consistent with these findings we found fewer $\mathrm{PV}+$ as well as other interneuron subtypes in the hippocampus of $\mathrm{Nrp2}^{-1-}$ mice compared to both $\mathrm{Nrp2}^{+/+}$and $\mathrm{Nrp2}^{+/-}$mice. $\mathrm{Nrp2}^{+/-}$and $\mathrm{Nrp2} 2^{-/-}$mice both showed deficits in the reversal-learning behavior task. While $\mathrm{Nrp2}^{+/-}$mice did not differ in the number of $\mathrm{PV}+$ hippocampal interneurons, they did have significantly fewer SOM + interneurons in the entire hippocampus compared to $\mathrm{Nrp}^{+/+}$mice. Future study is required to determine the roles of specific interneuron subtypes in the hippocampus and their relation to reversal learning.

Both inhibitory interneuron deficiency in the hippocampus and behavioral inflexibility have been associated with ASD [46, 56-58]. "Inflexible adherence to routines" is included as part of the DSM V requirements for diagnosing autism [45]. In a reversal-learning task, individuals with autism had difficulty maintaining reversals compared to controls [58]. Similarly, mice with a mutation an autism candidate gene, NrCam, experienced deficiencies in reversal learning but not acquisition learning in a Morris water maze test [59]. Here, we have demonstrated that mice with deficiencies in the autism candidate gene Nrp2 have deficits in reversal-learning strategies leading to impaired cognitive flexibility.

In summary, our studies identify that deletion of Nrp2, a gene with known polymorphisms in patient populations with autistic syndromes, contributes to a broad reduction in $\mathrm{PV}+, \mathrm{SOM}+$, and $\mathrm{NPY}+$ interneuron numbers in the hippocampal CA1 and compromises synaptic inhibition. We demonstrate that these circuitlevel disruptions in inhibition contribute to increased epileptogenicity and impaired cognitive flexibility, a hallmark of autism spectrum disorders. Our findings in mice with global Nrp2 deletion provide a strong foundation for future studies examining how interneuron-specific and developmental deletion of Nrp2 can impact cortical and hippocampal inhibitory circuit formation and their role in neuropsychiatric disorders. Taken together, our results indicate that reduced Nrp2 signaling impacts the development of interneurons circuits contributing to autism-epilepsy comorbidity.

\section{REFERENCES}

1. Jeste SS, Tuchman R. Autism spectrum disorder and epilepsy: two sides of the same coin? J Child Neurol. 2015;30:1963-71.

2. Stafstrom CE, Benke TA. Autism and epilepsy: exploring the relationship using experimental models. Epilepsy Curr. 2015;15:206-10.

3. Brooks-Kayal A. Molecular mechanisms of cognitive and behavioral comorbidities of epilepsy in children. Epilepsia. 2011;52(Suppl 1):13-20.

4. Brooks-Kayal A. Epilepsy and autism spectrum disorders: are there common developmental mechanisms? Brain Dev. 2010;32:731-8.

5. Tuchman R, Moshe SL, Rapin I. Convulsing toward the pathophysiology of autism. Brain Dev. 2009;31:95-103.

6. Sgado P, Dunleavy M, Genovesi S, Provenzano G, Bozzi Y. The role of GABAergic system in neurodevelopmental disorders: a focus on autism and epilepsy. Int J Physiol, Pathophysiol Pharmacol. 2011;3:223-35.

7. Huber $A B$, Kolodkin AL, Ginty DD, Cloutier JF. Signaling at the growth cone: ligand-receptor complexes and the control of axon growth and guidance. Annu Rev Neurosci. 2003;26:509-63.

8. Tran TS, Kolodkin AL, Bharadwaj R. Semaphorin regulation of cellular morphology. Annu Rev Cell Dev Biol. 2007;23:263-92.

9. Kolodkin AL, Tessier-Lavigne M. Mechanisms and molecules of neuronal wiring: a primer. Cold Spring Harb Perspect Biol. 2011;3:a001727.

10. Hou ST, Jiang SX, Smith RA. Permissive and repulsive cues and signalling pathways of axonal outgrowth and regeneration. Int Rev Cell Mol Biol. 2008;267:125-81.
11. Kim S, Chiba A. Dendritic guidance. Trends Neurosci. 2004;27:194-202.

12. Koropouli E, Kolodkin AL. Semaphorins and the dynamic regulation of synapse assembly, refinement, and function. Curr Opin Neurobiol. 2014;27:1-7.

13. Danelon V, Goldner R, Martinez E, Gokhman I, Wang K, Yaron A, et al. Modular and distinct Plexin-A4/FARP2/Rac1 signaling controls dendrite morphogenesis. J Neurosci. 2020:40:5413-30.

14. Nóbrega-Pereira S, Kessaris N, Du T, Kimura S, Anderson SA, Marín O. Postmitotic Nkx2-1 controls the migration of telencephalic interneurons by direct repression of guidance receptors. Neuron. 2008;59:733-45.

15. Butt SJ, Fuccillo M, Nery S, Noctor S, Kriegstein A, Corbin JG, et al. The temporal and spatial origins of cortical interneurons predict their physiological subtype. Neuron. 2005;48:591-604.

16. Tricoire L, Pelkey KA, Erkkila BE, Jeffries BW, Yuan X, McBain CJ. A blueprint for the spatiotemporal origins of mouse hippocampal interneuron diversity. J Neurosci: Off J Soc Neurosci. 2011;31:10948-70.

17. Takano T. Interneuron dysfunction in syndromic autism: recent advances. Dev Neurosci. 2015;37:467-75.

18. Sun C, Mtchedlishvili Z, Bertram EH, Erisir A, Kapur J. Selective loss of dentate hilar interneurons contributes to reduced synaptic inhibition of granule cells in an electrical stimulation-based animal model of temporal lobe epilepsy. J Comp Neurol. 2007;500:876-93.

19. Gant JC, Thibault O, Blalock EM, Yang J, Bachstetter A, Kotick J, et al. Decreased number of interneurons and increased seizures in neuropilin 2 deficient mice: implications for autism and epilepsy. Epilepsia. 2009;50:629-45.

20. Shiflett MW, M. G, Tran TS. Altered hippocampal-dependent memory and motor function in neuropilin 2-deficient mice. Transl Psychiatry. 2015;5:e521.

21. Ratnapriya R, Vijai J, Kadandale JS, lyer RS, Radhakrishnan K, Anand A. A locus for juvenile myoclonic epilepsy maps to 2q33-q36. Hum Genet. 2010;128:123-30.

22. Wu S, Yue W, Jia M, Ruan Y, Lu T, Gong X, et al. Association of the neuropilin-2 (NRP2) gene polymorphisms with autism in Chinese Han population. Am J Med Genet B Neuropsychiatr Genet. 2007;144B:492-5.

23. Hosseinpour M, Mashayekhi F, Bidabadi E, Salehi Z. Neuropilin-2 rs849563 gene variations and susceptibility to autism in Iranian population: A case-control study. Metab Brain Dis. 2017;32:1471-4.

24. Sahay A, Kim $C H$, Sepkuty JP, Cho E, Huganir RL, Ginty DD, et al. Secreted semaphorins modulate synaptic transmission in the adult hippocampus. J Neurosci. 2005;25:3613-20.

25. Li Z, Jagadapillai R, Gozal E, Barnes G. Deletion of Semaphorin 3F in Interneurons Is Associated with Decreased GABAergic Neurons, Autism-like Behavior, and Increased Oxidative Stress Cascades. Mol Neurobiol. 2019;56:5520-38.

26. Meyza K, Nikolaev T, Kondrakiewicz K, Blanchard DC, Blanchard RJ, Knapska E. Neuronal correlates of asocial behavior in a BTBR T $(+)$ Itpr3(tf)/J mouse model of autism. Front Behav Neurosci. 2015;9:199.

27. Dulla CG, Coulter DA, Ziburkus J. From molecular circuit dysfunction to disease: case studies in epilepsy, traumatic brain injury, and Alzheimeras disease. Neuroscientist. 2015;22:295-312.

28. Takano H, Coulter DA. in Jasper's Basic Mechanisms of the Epilepsies (eds JL Noebels et al.) (2012).

29. Coulter DA. Epilepsy-associated plasticity in gamma-aminobutyric acid receptor expression, function, and inhibitory synaptic properties. Int Rev Neurobiol. 2001;45:237-52.

30. Tran TS, Rubio ME, Clem RL, Johnson D, Case L, Tessier-Lavigne M, et al. Secreted semaphorins control spine distribution and morphogenesis in the postnatal CNS Nature. 2009;462:1065-9.

31. Pasterkamp RJ, Giger RJ. Semaphorin function in neural plasticity and disease. Curr Opin Neurobiol. 2009;19:263-74.

32. Gavazzi I. Semaphorin-neuropilin-1 interactions in plasticity and regeneration of adult neurons. Cell Tissue Res. 2001;305:275-84.

33. Giger RJ, Cloutier JF, Sahay A, Prinjha RK, Levengood DV, Moore SE, et al. Neuropilin-2 is required in vivo for selective axon guidance responses to secreted semaphorins. Neuron. 2000;25:29-41.

34. Flurkey K, Currer JM, Harrison DE "The Mouse in Biomedical Research, 2nd ed. Volume 3, Normative Biology, Husbandry, and Moedels", in James G. Fox (ed.), American College of Laboratory Animals Medicine series (Elsevier, AP; Amsterdam; Boxton). (2007).

35. Assous M, Martinez E, Eisenberg C, Shah F, Kosc A, Varghese K, et al. Neuropilin 2 signaling mediates corticostriatal transmission, spine maintenance, and goaldirected learning in mice. J Neurosci. 2019;39:8845-59.

36. Yu J, Proddutur A, Swietek B, Elgammal FS, Santhakumar V. Functional reduction in cannabinoid-sensitive heterotypic inhibition of dentate basket cells in epilepsy: impact on network rhythms. Cereb Cortex. 2016;26:4229-314.

37. Gupta A, Proddutur A, Chang YJ, Raturi V, Guevarra J, Shah Y, et al. Dendritic morphology and inhibitory regulation distinguish dentate semilunar granule cells from granule cells through distinct stages of postnatal development. Brain Struct Funct. 2020;225:2841-55. 
38. Yu J, Swietek B, Proddutur A, Santhakumar V. Dentate total molecular layer interneurons mediate cannabinoid-sensitive inhibition. Hippocampus. 2015;25:884-9.

39. Korgaonkar AA, Li Y, Sekhar D, Subramanian D, Guevarra J, Swietek B, et al. Tolllike receptor 4 signaling in neurons enhances calcium-permeable alpha-amino-3hydroxy-5-methyl-4-isoxazolepropionic acid receptor currents and drives posttraumatic epileptogenesis. Ann Neurol. 2020;87:497-515.

40. Racine RJ. Modification of seizure activity by electrical stimulation. II. Motor seizure. Electroencephalogr Clin Neurophysiol. 1972;32:281-94.

41. Tse K, Puttachary S, Beamer E, Sills GJ, Thippeswamy T. Advantages of repeated low dose against single high dose of kainate in C57BL/6J mouse model of status epilepticus: behavioral and electroencephalographic studies. PLoS ONE. 2014;9: e96622.

42. Marin O, Yaron A, Bagri A, Tessier-Lavigne M, Rubenstein JL. Sorting of striatal and cortical interneurons regulated by semaphorin-neuropilin interactions. Science. 2001;293:872-5.

43. Freund TF, Buzsaki G. Interneurons of the hippocampus. Hippocampus. 1996;6:347-470.

44. Klausberger T, Somogyi P. Neuronal diversity and temporal dynamics: the unity of hippocampal circuit operations. Science. 2008;321:53-57.

45. American Psychiatric Association. (2013). Diagnostic and statistical manual of mental disorders (5th ed.).

46. Landry O, Mitchell P. An examination of perseverative errors and cognitive flexibility in autism. PLoS ONE. 2021;16:e0223160.

47. Jacob J. Cortical interneuron dysfunction in epilepsy associated with autism spectrum disorders. Epilepsia. 2016;57:182-93.

48. Chaby LE, Karavidha K, Lisieski MJ, Perrine SA, Liberzon I. Cognitive Flexibility Training Improves Extinction Retention Memory and Enhances Cortical Dopamine With and Without Traumatic Stress Exposure. Front Behav Neurosci. 2019;13:24.

49. D'Cruz A-M, Mosconi MW, Ragozzino ME, Cook EH, Sweeney JA. Alterations in the functional neural circuitry supporting flexible choice behavior in autism spectrum disorders. Transl Psychiatry. 2016;6:e916.

50. Vilà-Balló A, Mas-Herrero E, Ripollés $P$, Simó $M$, Miró J, Cucurell D, et al. Unraveling the Role of the Hippocampus in Reversal Learning. J Neurosci. 2017;37:6686-97.

51. Havekes R, Nijholt IM, Luiten PG, Van der Zee EA. Differential involvement of hippocampal calcineurin during learning and reversal learning in a Y-maze task. Learn Mem. 2006;13:753-9.

52. Cohen JS, Telegdy GA. Reversal- and non-reversal-shift discrimination learning as a function of drive in albino rats. Psychol Rep. 1974;34:447-52.

53. Mickley GA, Ferguson JL, Mulvihill MA, Nemeth JJ. Progressive behavioral changes during the maturation of rats with early radiation-induced hypoplasia of fascia dentata granule cells. Neurotoxicol Teratol. 1989;11:385-93.

54. Murray EA, Baxter MG, Gaffan D. Monkeys with rhinal cortex damage or neurotoxic hippocampal lesions are impaired on spatial scene learning and object reversals. Behav Neurosci. 1998;112:1291-303.

55. Morellini F, Sivukhina E, Stoenica L, Oulianova E, Bukalo O, Jakovcevski I, et al. Improved reversal learning and working memory and enhanced reactivity to novelty in mice with enhanced GABAergic innervation in the dentate gyrus. Cereb Cortex. 2010;20:2712-27.

56. Fu C, Cawthon B, Clinkscales W, Bruce A, Winzenburger P, Ess KC. GABAergic interneuron development and function is modulated by the Tsc1 gene. Cereb Cortex. 2012;22:2111-9.

57. Wiebe S, Nagpal A, Truong VT, Park J, Skalecka A, He AJ, et al. Inhibitory interneurons mediate autism-associated behaviors via 4E-BP2. Proc Natl Acad Sci USA. 2019;116:18060-7.
58. D'cruz AM, Ragozzino ME, Mosconi MW, Shrestha S, Cook EH, Sweeney JA. Reduced behavioral flexibility in autism spectrum disorders. Neuropsychology. 2013;27:152-60.

59. Moy SS, Nonneman RJ, Young NB, Demyanenko GP, Maness PF. Impaired sociability and cognitive function in Nrcam-null mice. Behav Brain Res. 2009;205:123-31.

\section{ACKNOWLEDGEMENTS}

The authors would like to thank Emma D. Eisenberg for her help in illustrating the schematic diagrams of the hippocampus in the manuscript. This work is supported by the NJ Governor's Council for Medical Research and Treatment of Autism: CAUT17BSP011 to V.S. and T.S.T., CAUT17BSP022 to T.S.T. and M.W.S., Rutgers Brain Health Initiative Pilot Grants to T.S.T. and V.S., NIH R01 NS069861 and NS097750 to V.S., and NSF/IOS: 1556968 to T.S.T.

\section{AUTHOR CONTRIBUTIONS}

C.E., D.S., M.A. P.Z., and J.D. performed the experiments with assistance from P.R.H.; C.E., D.S., M.A., M.W.S., V.S., and T.S.T. analyzed the data and interpreted the results; C.E., D.S., and M.A. prepared the figures; M.W.S., V.S., and T.S.T. conceptualized and designed the research; V.S. and T.S.T. wrote the manuscript with feedbacks from all co-authors.

\section{COMPETING INTERESTS}

The author declares no competing interests.

\section{ADDITIONAL INFORMATION}

Correspondence and requests for materials should be addressed to Vijayalakshmi Santhakumar or Tracy S. Tran.

Reprints and permission information is available at http://www.nature.com/ reprints

Publisher's note Springer Nature remains neutral with regard to jurisdictional claims in published maps and institutional affiliations.

(i) Open Access This article is licensed under a Creative Commons adaptation, distribution and reproduction in any medium or format, as long as you give appropriate credit to the original author(s) and the source, provide a link to the Creative Commons license, and indicate if changes were made. The images or other third party material in this article are included in the article's Creative Commons license, unless indicated otherwise in a credit line to the material. If material is not included in the article's Creative Commons license and your intended use is not permitted by statutory regulation or exceeds the permitted use, you will need to obtain permission directly from the copyright holder. To view a copy of this license, visit http://creativecommons. org/licenses/by/4.0/.

This is a U.S. government work and not under copyright protection in the U.S.; foreign copyright protection may apply 2021 